NBER WORKING PAPER SERIES

\title{
COHORT CROWDING AND YOUTH \\ LABOR MARKETS: A CROSS-NATIONAL \\ ANALYSIS
}

\author{
Sanders Korenman \\ David Neumark
}

Working Paper 6031

\section{NATIONAL BUREAU OF ECONOMIC RESEARCH 1050 Massachusetts Avenue \\ Cambridge, MA 02138 \\ May 1997}

We are grateful to Danny Blanchflower for assistance with the data, to Daniel Hansen for outstanding research assistance, and to Danny Blanchflower, Richard Freeman, Ted Joyce, Thomas Lemieux, and Klaus Zimmerman for helpful comments. Neumark's research was partially supported by NIA grant K01-AG00589. This paper was prepared for the NBER conference "Youth Unemployment and Employment in Advanced Countries." This paper is part of NBER's research program in Labor Studies. Any opinions expressed are those of the authors and not those of the National Bureau of Economic Research.

(C) 1997 by Sanders Korenman and David Neumark. All rights reserved. Short sections of text, not to exceed two paragraphs, may be quoted without explicit permission provided that full credit, including $(\mathcal{C}$ notice, is given to the source. 
Cohort Crowding and Youth Labor Markets:

A Cross-National Analysis

Sanders Korenman and David Neumark

NBER Working Paper No. 6031

May 1997

JEL Nos. J11, J21

Labor Studies

\begin{abstract}
$\underline{\text { ABSTRACT }}$
We assess the evidence on the contribution of changes in the population age structure to the changing fortunes of youths in labor markets in the advanced economies over the $1970 \mathrm{~s}, 1980 \mathrm{~s}$, and early 1990s, and use this evidence to project the likely effects of future cohort sizes on youth labor markets. We estimate a series of regression models in order to isolate the effects of exogenous changes in potential youth labor supply on youth employment and unemployment rates, using a panel data set on 15 countries over more than 20 years. Our preferred estimates indicate that large youth cohorts lead to increases in the unemployment rate of youths, with elasticities as high as .5 or .6. On the other hand, the estimates generally indicate little effect of relative cohort size on employment rates of youths. We also find some evidence, although it is statistically weak, to suggest that labor market institutions that decrease flexibility lead to sharper responses of youth unemployment and employment rates to fluctuations in youth cohort size. Finally, due to recent declines in fertility, several European countries will experience marked reductions in the size of youth cohorts over the next 16 years (especially Ireland, Italy, Portugal, and Spain). Projections suggest that declining youth shares should improve youth labor markets in these countries, although the effects are not large compared with longer-term changes in youth unemployment rates. Other countries cannot expect demographic changes to improve youth labor markets since youth population shares are projected to decline moderately or to increase.
\end{abstract}

Sanders Korenman

School of Public Affairs

Baruch College, CUNY

17 Lexington Avenue, Box F-2021

New York, NY 10010

and NBER

korenman@newton.baruch.cuny.edu
David Neumark

Department of Economics

Michigan State University

East Lansing, MI 48824

and NBER

dneumark@msu.edu 


\section{Introduction}

Among the advanced economies, the European countries face a youth employment crisis. Over the period 1970-1994 the average unemployment rate for youths aged 15 to 24 in the 11 European countries studied in this paper rose by over 16 percentage points (from 4.2 to 20.6 percent), while the average unemployment rate for adults aged 25 to 54 rose from 1.6 to 9.7 percent. ${ }^{1}$ In contrast, in the U.S. in this period the youth unemployment rate rose from 11.0 to 12.5 percent, and the adult rate from 3.4 to 5 percent. Over the same period, the average youth employment rate in these European countries fell from 59 percent to 41 percent, while adult employment rates were generally flat or increasing. The deterioration of the youth labor market has been particularly severe in Finland, France, Ireland, Italy, Spain, and Sweden. The poor performance of the labor market for youths is in part due to aggregate cyclical fluctuations, with the most recent sharp increases in youth unemployment and decreases in youth employment in some countries (especially Finland and Sweden) likely to at least partially reverse course. However, the longer-term trends suggest that the youth employment crisis goes beyond cyclical changes, and may be symptomatic of more lasting changes such as those that have affected the wage structure, favoring the more highly-educated work force over those with fewer "skills," including favoring older workers over younger, less-experienced workers. This concern raises the obvious question of what steps, if any, might be taken to ease the youth employment crisis.

Rather than focusing on policies to address youth employment problems, the purpose of this paper is to assess the evidence on the contribution of changes in the population age structure to the changing fortunes of youths in the labor market over the 1970s, 1980s, and early 1990s, and to use this evidence to project the likely effects of future cohort sizes on youth labor markets. This is intended to serve as a backdrop for broader labor market policy 
questions, by providing evidence on the extent to which youth labor market problems may be ameliorated by demographic change. A casual reading of the evidence does not provide cause for optimism that demographic developments--in particular, projected declines in the size of young cohorts--will improve youth labor markets. Many countries experienced baby busts in the 1960s that produced relatively small entering cohorts in the 1980s and 1990s. For example, the ratio of the youth population to the adult population fell from .43 to .29 in the U.S. and from .51 to .28 in Finland from 1970 to 1994 , while falling from .48 to .30 in the Netherlands from 1971 to 1994 . These changes in the population age structure should have improved the labor market position of youths relative to older adults, as long as younger and older workers are not perfect substitutes in production. However, this period brought continuing deterioration of the youth labor market in many countries, rather than improvement. Why did youths do so poorly during a period when they became more scarce? One possible explanation is that the effects of changes in demand for young workers in this period due to downturns in the business cycle, technological changes, and changing patterns of international trade swamped the beneficial effects of supply-side changes. To some extent, this appears to be the case, as our results ultimately suggest that the independent effect of declines in relative youth cohort size is to improve the youth labor market.

We first review the recent literature on the effects of cohort size on labor market outcomes of youths. We then provide a descriptive overview of changes in population structure and youth labor markets. Following that, we turn to estimates of a series of regression models that attempt to isolate the effects of exogenous changes in potential youth labor supply on youth employment and unemployment rates, using a panel data set for 15 countries over more than 20 years.

Although there is a large literature in this area, we offer a number of innovations, as 
well as new information. First, we use a cross-national time-series sample that extends into the 1990s. This sample allows us to take advantage of variation across countries in the timing and magnitude of changes in youth cohort sizes to estimate cohort size effects, to better isolate the effects of cohort size from general trends that may have affected all young people during this period (for example, rising relative demand for skilled labor).

Second, we address problems of potential bias from endogenous determination of relative youth cohort size in a country. In particular, we correct for the influence of endogenous migration decisions of youth and adults by using lagged births as an instrument for our measure of relative cohort size (the ratio of the youth population to the adult population).

Third, we estimate models that allow cohort size effects to vary according to the state of the macroeconomy, testing whether economies with tighter aggregate labor markets are able to absorb large cohorts more readily than those with slack aggregate labor markets.

Fourth, we carry out a variety of specification tests and sensitivity analyses, focusing on the specification of the error term, possible correlations between omitted variables and relative cohort size, and the appropriate dynamics.

Fifth, we relate the institutional features of labor markets to responses to population change. In particular, we focus on the effects of centralization in wage setting, and the influence of policies (such as unemployment benefits) that may affect wage adjustments or the allocation of labor. We find some evidence, although it is statistically weak, to suggest that labor market institutions that decrease flexibility lead to greater response of youth unemployment and employment rates to fluctuations in youth cohort size.

The results are somewhat sensitive to alterations in estimation and specification, so the choice of estimation strategy affects the conclusions. Our preferred estimates indicate that large youth cohorts lead to large increases in the relative unemployment rate of youths, with 
elasticities as high as .5 or .6 . On the other hand, we find little effect of relative cohort size on relative employment rates of youths.

Finally, we carry out a series of projections. Due to recent drops in fertility, several European countries (especially Ireland, Italy, Portugal, and Spain), as well as Japan, will experience marked reductions in the size of youth cohorts over the next 16 years. Projected declines of youth shares should improve youth labor markets in these countries, although the effects are not large compared with longer-term changes in youth unemployment rates. Moreover, for countries that have experienced slack demand (reflected in rising adult unemployment rates), the improvements in youth labor markets from declining youth cohort sizes are small relative to the improvements that could be gained from increases in economic activity that reduce adult unemployment rates to earlier levels. Other countries cannot expect demographic changes to improve youth labor markets since youth population shares are projected to decline moderately (the U.S., Finland, France, the Netherlands, and Australia) or to increase (Germany, Norway, Sweden, the U.K., and Canada). Thus, population change will probably do relatively little to reduce youth employment problems in the advanced economies.

\section{Previous Literature on Cohort Size and Youth Labor Markets}

In this section we review the literature on the effects of cohort size, with an emphasis on recent research. Although the empirical research in this paper examines effects on youth employment and unemployment only, our review also covers studies that estimate effects of relative cohort size on wages, in part because the employment and unemployment effects that we study may depend in part on wage changes induced by demographic changes.

Bloom, et al. (1987) summarize 18 studies of the effects of cohort size on labor markets for youths. All the studies they review present evidence of some adverse effects of own cohort 
size on the relative wages or employment of youth. They conclude that:

Despite differences across studies, two clear areas of agreement emerge. First, in the U.S., Canada, and Israel, the entry of relatively large cohorts into the labor market did result in a decline in the earnings of those cohorts relative to the earnings of older, smaller cohorts. Second, the labor market entry of large cohorts tended to result in increased relative unemployment in most countries.

Most studies have relied on time-series variation in cohort size to estinate cohort size effects. Very few studies have taken advantage of cross-national variation in the size and timing of demographic fluctuations. Many studies note that there is potential confounding of cohort (size) and various period effects, especially those related to the business cycle (Fair and Dominguez, 1991; Borsch-Supan, 1993). The confounding of period and cohort effects is a particular concern in samples that cover short periods, and those in which variation in cohort size is limited or where cohort size is trending smoothly.

The potential value of examining cross-national variation in demographic cycles is obvious. For example, in the U.S. the period 1973 to 1984 was one of economic stagnation ending with a severe recession. Youths who reached age 20 between 1973 and 1984 were born between 1953 and 1964, a period containing the peak and trailing end of the U.S. baby boom. It is difficult with time-series evidence alone to determine the relative importance of two explanations of the labor market problems experienced by these baby-boom cohorts in their youth: large cohort size and poor aggregate economic conditions at the time of labor market entry (Fair and Dominguez, 1991). However, fertility fluctuations were of different magnitudes and occurred at different times in different countries. As a result, fluctuations in labor supply due to the entry of young cohorts into the labor market also took place at different times. If cohort crowding is responsible for the adverse outcomes for large cohorts, then large cohorts should have poor outcomes in all economic environments. The cross-national approach should therefore provide a better test of the cohort crowding hypothesis. 
Bloom, et al. (1987) also conducted original analyses of a pooled cross-country crossyear sample. This is the only study we are aware of that takes advantage of cross-national variation in cohort sizes to estimate their effects. ${ }^{2}$ (In the present paper, we are able to use data for a longer sample period, which exploits variation in cohort size in the 1980 s and early 1990s produced by the baby bust in several countries in our data set.) Bloom, et al. find that the expected relative wage (defined as the product of earnings and the employment rate) is lower for large cohorts. They also find evidence of a trade-off between relative employment and earnings: large youth cohorts experienced depressed earnings (e.g., in the U.S.) or increased relative unemployment rates (e.g., in Europe). Large youth cohorts appear to have been absorbed in all major industries, not simply through the expansion of youth-intensive industries, such as the service sector.

Bloom, et al. also examine whether, in the U.S., labor market disadvantages experienced in youth by large cohorts are permanent, by tracking the progress of large cohorts using the 1969 to 1984 Current Population Surveys (CPS). They present evidence that the baby boom cohorts were able to "catch up," partly in relative wages, and completely in relative unemployment rates, within about a decade of labor market entry. Nonetheless, even though large cohorts may eventually obtain the economic status of smaller cohorts, large cohorts have lower lifetime wealth due to earnings lost during the catch-up period.

Several recent studies of cohort size effects have taken up the following questions (some of which were also discussed in earlier literature):

1. Do the same patterns of cohort size effects found mostly in studies of the U.S. appear in data for other countries?

2. Do the effects of cohort size on wages or employment persist?

3. How do demographic fluctuations (the size of own and surrounding cohorts) affect 
the shape of age-earnings or experience-earnings profiles? How do they affect investment in human capital?

4. Are cohort size effects larger for the more-educated members of cohorts?

The findings from many of these recent studies are summarized in Table $1 .{ }^{3}$ Although researchers have examined different aspects of cohort size effects on young workers using different samples and estimation techniques, it is possible to offer a tentative synthesis with respect to these questions. There seems to be evidence for an adverse effect of cohort size on youth unemployment, employment, and wages, across a number of countries. There is also some consensus about the persistence of such effects; estimates run from partial to nearly full "catch up." Several authors predict that cohort size effects may differ depending on a cohort's "position" in the demographic cycle, although the evidence for this proposition is more mixed. Cohort size effects do appear to be stronger for more-educated workers. In addition to these findings, there is also speculation based mainly on indirect evidence that the adverse effects of large cohort size are smaller for cohorts that happen to enter the labor market during favorable demand conditions. Finally, some authors have expressed concerns about endogeneity of relative cohort size due to various behavioral responses to cohort crowding such as migrating or delaying age of school leaving (when a relative labor force size variable is used), although this issue has not been adequately addressed. In the empirical work that follows, we consider evidence on many of these issues.

\section{Empirical Analysis}

\section{The Data}

Most of the data we examine are from the U.S., Canada, Australia, Japan, and the 11 European countries for which the OECD publishes time-series data on the variables used in this study for most or all of the period 1970 through $19944^{4}$ The majority of the data on 
population, unemployment and employment rates are from Labor Force Statistics, Part III and Employment Outlook, July 1995, Statistical Annex, both published by the OECD. ${ }^{5}$ Population data for the United Kingdom prior to 1984 are from the Demographic Yearbook published by the United Nations. Employment and unemployment data for the U.K. prior to 1984 are from the aforementioned OECD sources, and include only England and Wales (after 1984, the entire U.K. is included in the data).

Youth ages are defined as 15 through 24, with the following exceptions: 14-24 in Italy, and 16-24 in the U.S., Norway, Spain, Sweden, and the U.K. Adult ages are defined as 2554 , except for Italy for which the range is $25-59 .{ }^{6}$ Relative cohort size is measured as (population 15-24)/(population 25-54).

GNP figures are from World Tables, published by the World Bank. The GNP growth rate is defined as $100 \cdot\left(\mathrm{GNP}_{\mathrm{t}}-\mathrm{GNP}_{\mathrm{t}-1}\right) / \mathrm{GNP}_{\mathrm{t}-1}$. All of the figures are real values. The data series for the GNP growth rate are generally shorter than those for the population and employment data. These data are from 1975 through 1993 for most of the countries in the sample. ${ }^{7}$

Data for lagged births for the European countries are from International Historical Statistics: Europe 1750-1988. The same data for the United States are from Vital Statistics of the United States 1991, published by the U.S. Department of Health and Human Services. Data for Japan and Australia come from International Historical Statistics: Africa, Asia and Oceania $^{8}$

Population projections are taken from World Population Prospects 1994-95 Edition, published by the World Bank. The projections are made in five-year intervals, beginning in 1995; we interpolate linearly to obtain estimates for each year. We have used the "mediumvariant projections" from 2000 through 2010. 


\section{A Look at the Time-Series Evidence by Country}

Figure 1 displays data on relative youth cohort size for the 15 countries in our data set from approximately 1970 through 1994 . The information displayed to the left of the vertical lines is the actual data, while that to the right of the vertical lines is projections, discussed in greater detail below. Looking first at the population share or relative cohort size variable, we

see that the U.S., Canada, Germany, Ireland, Portugal, and the U.K. experienced a baby boom followed by a bust, reflected in relative youth cohort sizes about 20 years later. Other countries--Finland, France, the Netherlands, Australia, and to some extent Sweden and Norway--have experienced fairly steady declines in the relative size of youth cohorts. Finally, in Italy and Spain there is no discernible trend, while Japan exhibits a sharp decline followed by a modest increase in the late 1980s and early 1990s. Based on the declines in relative youth cohort sizes over the latter part of the sample period (for all countries except Italy, Spain, and Japan), if smaller cohorts increase labor market prospects for young workers, then we should have seen higher youth employment rates and lower youth unemployment rates in recent years. Moreover, youth cohorts are projected to shrink in relative size for many of the countries-especially Ireland, Italy, Portugal, Spain, and Japan. Thus, the cohort crowding hypothesis would suggest future improvements in youth labor markets in these countries.

However, data on youth unemployment and employment rates, depicted in Figures 2 and 3 (displayed along with the data on relative cohort size) raise doubts about the cohort crowding hypothesis. Figure 2, for example, shows youth unemployment rates (indicated by circles, whereas the population shares are indicated by solid lines). In some countries with declining or steady relative youth cohort size, youth unemployment rates rose steadily throughout the sample period (France and Ireland) or jumped towards the end of the period (Finland and Sweden, and to a lesser extent Australia and Canada). Similar phenomena are 
reflected in the youth employment rates displayed in Figure 3. More generally, what we expect to see in these figures, if the cohort crowding hypothesis holds, is that (all else the same) youth unemployment rates and relative cohort size move in the same direction, whereas youth employment rates and relative cohort size move in opposite directions. With respect to unemployment, this prediction appears to be contradicted for Finland, France, Germany, Ireland, Norway, Australia, and Canada, and for the early part of the sample period for the Netherlands. With respect to employment, this prediction appears to be contradicted for nearly all countries with the exceptions of Germany, Spain, and the U.K., as well as the Netherlands in the latter part of the sample period.

Of course, relative youth cohort size is not the only variable affecting youth unemployment or employment rates. Aggregate demand effects are likely to be important. In the regression estimates discussed below, we include aggregate demand controls. In Figures 4 and 5 , we foreshadow the results by showing the ratio of the youth unemployment or employment rate to the corresponding adult rate. These ratios will reduce the influence of aggregate changes that are also reflected in the adult rates, although they will not eliminate all aggregate influences, because youth unemployment and employment rates are more cyclically sensitive (Clark and Summers, 1982). The relative unemployment rates graphed in Figure 4 exhibit smaller movements; notably, the sharp increases in the unemployment rate in the last few years in Finland and Sweden, and the increase over a longer period in Spain, are not reflected in the unemployment rate ratios, suggesting that aggregate developments are an important contributor to changes in youth unemployment. Figure 4 appears to provide a little more support for the cohort crowding hypothesis, as relative youth unemployment rates and cohort size move in the same direction for more countries and longer sample sub-periods. In contrast, the relative employment rates in Figure 5 display time-series behavior similar to the 
absolute rates in Figure 3, generally reflecting worsening youth labor markets coupled with declining youth cohort size.

\section{The Intervening Role of Schooling}

It is possible, however, that the employment declines in Figure 5 reflect trends in schooling or other labor market alternatives, and therefore do not necessarily represent a social problem. Of course, it is difficult to untangle increased enrollment for exogenous reasons from increased enrollment that is spurred by slack labor markets for youths (for reasons other than demographic developments, which should have improved youth labor markets in many countries). Although this paper does not provide a detailed analysis of the relationships between youth enrollment, employment, and unemployment, and demographic change, a cursory look at the evidence is nonetheless instructive.

Figure 6 plots relative youth cohort size and enrollment rates, based on school enrollment data for a subset of the countries for which the OECD has made such data available. ${ }^{9}$ For the countries included in Figure 6, those in which relatively strong declines in youth cohort size were not accompanied by increases in either the relative or absolute youth employment rate include France, Ireland, Portugal, and to a lesser extent Australia (see Figures 3 and 5). As Figure 6 shows, however, in all four of these countries there were rather steep increases in enrollment rates in the period for which the data are available. At the same time, among the countries in which youth employment rates and cohort size do appear to have a negative association, including Germany, Spain, the U.K., the Netherlands, and to a lesser extent the U.S. and Canada, most had small increases in enrollment rates (the U.S., Germany, the Netherlands, and the U.K.). Thus, failure to account for sources of changes in enrollment rates that in turn affect employment rates may help to explain the apparent lack of evidence for a negative relationship between youth employment rates and relative cohort size. 
As additional evidence, Figure 7 plots youth enrollment rates and employment rates. It is the case that some of the countries with steep declines in youth employment also experienced sharp increases in youth enrollment. However, it is not true that youth enrollment rates simply reflect the reverse of youth employment rates. While youth enrollment and employment rates generally moved in opposite directions, there are contrary occurrences, such as the U.K. and the Netherlands. Below, we look briefly at the implications of changes in enrollment rates within the regression framework in which we analyze the cohort crowding hypothesis more thoroughly.

Of course, nothing in this analysis says that the changes in youth enrollment rates were exogenous, and therefore "explain" the failure of youth employment rates to conform to the cohort crowding hypothesis. The data are equally consistent with youth employment rates falling in some countries despite declining youth cohort size, and with enrollment rates rising in response to poor labor market prospects. Attempting to untangle the causality is a task for future research.

\section{Grouping Countries by History of Cohort Size Changes}

In the next set of figures (8-11), we aggregate countries according to their decade-bydecade changes in age structure. The countries are grouped into each of three categories for the 1970 s and then for the 1980 s and beginning of the 1990s: those in which a baby-boom cohort reached the youth ages; those in which a baby-bust cohort reached these ages; and those with little trend in relative youth cohort size. ${ }^{10}$ Figures 8 through 11 display, respectively, youth unemployment rates, youth employment rates, relative (youth/adult) youth unemployment rates, and relative youth employment rates for the six groups of countries. According to the cohort crowding hypothesis, youth labor market outcomes should deteriorate more (improve less) in periods when youth cohorts are increasing in size as compared to 
periods when they are decreasing in size or there is little variation in youth cohort size.

Consistent with the hypothesis, countries where a baby-boom cohort entered the labor market in the 1970s experienced larger increases in youth unemployment than those where there was a baby-bust cohort or little trend in cohort size (first row of graphs in Figure 8). Similarly, in the 1980s and 1990s countries in which a baby-bust cohort entered the labor market experienced a smaller increase in youth unemployment than countries with little trend, although the one country (Japan) in which a baby-boom cohort entered did not experience a sharper rise in youth unemployment (second row, Figure 8, looking to the right of the vertical lines). Figure 9 shows the relative (youth/adult) unemployment rate for the same set of countries. Here, too, the evidence is generally consistent with the cohort crowding hypothesis, at least as regards the comparison between boom and bust countries. For example, in the 1970s relative youth unemployment rates rose considerably more for those countries in which a boom cohort entered the labor market, compared with those in which a bust cohort entered.

Figures 10 and 11 turn to youth employment rates. Here, there is much less evidence consistent with cohort crowding. In the 1970 s employment rates (or relative employment rates) decline for boom and bust countries, although more so for the former. In the 1980s and early 1990s, however, youth employment rates (relative or absolute) rose for the boom countries, and fell for the other countries, inconsistent with the cohort crowding hypothesis.

\section{Interpretation}

The data displayed in Figures 2-11 lead to some tentative conclusions. First, youth unemployment rates appear to respond to changes in the relative sizes of youth cohorts in ways predicted by the cohort crowding hypothesis. On the other hand, youth employment rates appear at least sometimes to move in the opposite direction, falling as relative cohort size declines, or are unrelated to relative cohort size. 
If wages are completely flexible, and the substitution effect dominates, then the employment rate should fall in response to the entry of a large cohort. Total employment of youths should increase, but at the lower equilibrium wage the employment rate should be lower as more youths choose not to work. ${ }^{11}$ On the other hand, unemployment of youths should not necessarily increase, at least insofar as the unemployment rate reflects involuntary unemployment. The results for both unemployment and employment appear to be inconsistent with this characterization of labor markets for youths and the effects of cohort size. In contrast, if wages are rigid, or, alternatively, there is a fixed stock of jobs for youths, then in response to the entry of a large youth cohort, the employment rate of youths should fall (more sharply than if wages are flexible), and the unemployment rate should rise. ${ }^{12}$ The evidence in Figures 2-11 appears to be consistent with the rigid wage characterization with respect to unemployment rates, but not employment rates.

In fact, we expect that the reality is somewhere between these two extremes, which is why we expect large youth cohorts to increase youth unemployment rates, and to decrease youth employment rates. Below, we look more closely at country differences in the response of youth unemployment and employment to demographic shifts, and attempt to link these responses to institutional characteristics of labor markets related to the flexibility of wages. First, though, we turn to a more systematic analysis of the panel data set.

\section{Analyzing the Panel Data}

We begin by presenting estimates of specifications that are relatively standard in the literature, in particular

$$
Y E_{i t}=R C S_{i t} \beta+A E_{i t} \gamma+D_{i t} \delta+\epsilon_{i t} \text {, }
$$

where $\mathrm{i}$ indexes country and $t$ indexes year, and all variables are in logs. YE is either the log 
of the youth unemployment rate or the youth employment rate, defined as the rate for 15-24 year-olds (for most countries). RCS is the log relative cohort size. We include different cyclical controls, including the log adult unemployment rate, the log adult employment rate, or other measures; these are denoted $\mathrm{AE} \cdot{ }^{13} \mathrm{D}$ is a vector of dummy variables capturing the timing of changes in the definitions of various series in the data set, some of which are described in the data section, and others of a more technical nature indicated in the original data sources.

We interpret equation (1) as a reduced form employment rate or unemployment rate equation, with the adult unemployment and employment variables capturing demand influences, and the relative cohort size variable capturing supply influences. Assuming that workers of different ages are imperfectly substitutable, and controlling for demand shifts, larger cohorts face lower wages. When the dependent variable is the youth employment rate, the cohort crowding hypothesis predicts that $\beta<0$. In contrast, when the dependent variable is instead the relative unemployment rate, the cohort crowding hypothesis predicts that $\beta>0$.

\section{Basic Regression Results}

In Table 2 we present estimates of the effects of relative youth cohort size on youth unemployment and employment rates, focusing on the appropriate specification of the error term in equation (1). We control for adult unemployment and employment rates. Panel A reports OLS estimates in which we treat the error term $\epsilon$ as orthogonal to the regressors, and independently (and identically) distributed both within and across countries. Larger relative youth cohort size is associated with a higher relative youth unemployment rate, as predicted by the cohort crowding hypothesis, although the estimated coefficient is small (.035) and not statistically significant. Larger relative youth cohort size is also associated with a higher relative youth employment rate (with the effect statistically significant), inconsistent with the 
cohort crowding hypothesis.

In Panel B we consider the inclusion of common country components in the error, reporting estimates from specifications with country-specific fixed effects. It seems plausible that there are country-specific factors (although they are not necessarily time-invariant) that influence relative youth unemployment and employment rates. ${ }^{14}$ In comparison to the OLS estimates in Panel A, the fixed-effects estimates indicate a much larger and significant positive effect of cohort size on youth unemployment rates, and a much smaller positive effect on youth employment rates. ${ }^{15}$

We next add fixed year effects, in Panel C, maintaining the fixed country effects specifications. Figure 3, discussed previously, shows a downward trend in the youth employment rates in many countries that will be captured by the year dummy variables. The inclusion of fixed year effects has little impact on the estimated equation for youth unemployment rates, as the estimated effect of relative cohort size is still positive and significant, with an elasticity of .29. However, the estimated effect of relative cohort size on youth employment rates becomes negative (and significant), as predicted by the cohort crowding hypothesis, with an elasticity of $-.11 .^{16}$

Thus, a plausible specification that appears to be consistent with the data (conditional on the specification of the observable variables), produces evidence consistent with the cohort crowding hypothesis. Large relative youth cohorts are associated with lower youth employment rates, and higher youth unemployment rates. Given the results in Panels A-C, in the remainder of the paper we estimate specifications with fixed country and fixed year effects.

Finally, we estimate specifications accounting for serially correlated errors, as well as fixed country and year effects. Such serial correlation renders the estimates in Panel C inefficient, and likely biases the estimated standard errors downward. Panel D of Table 2 
reports estimates incorporating an $\mathrm{AR}(1)$ process into the error term of equation (1) ${ }^{17}$ The estimated effect of relative cohort size on the youth unemployment rate falls to .18 , which, coupled with a sizable increase in the standard error, is not significant. In the equation for the youth employment rate, the sign of the estimated coefficient reverts to being positive, inconsistent with the cohort crowding hypothesis. The high estimated degree of autocorrelation in the data (with the estimates of the first-order serial correlation parameter ranging from .65 to .86 ) suggests that the AR(1) error specification is preferred; we therefore maintain it in the analyses that follow. ${ }^{18}$

\section{Endogeneity of the Relative Cohort Size Variable}

In the next set of analyses we explore the importance of potential endogeneity of the relative cohort size variable. In particular, the youth population (and to a lesser extent the adult population) may be endogenous if immigration flows respond to labor market conditions. In Panel A of Table 3 we address the endogeneity of the youth population, by instrumenting for relative cohort size with the ratio of lagged births (i.e., births from the years in which the current youth cohort was born) to the adult population. ${ }^{19}$ If we expect the currently-resident youth population to be relatively larger when youth labor markets are doing well, then the relative cohort size variable will be positively correlated with the youth employment rate, biasing the estimate of $\beta$ upward in the regressions for the employment rate. Similarly, the estimate of $\beta$ would be biased downward in the regressions for the youth unemployment rate.

In the first row of Panel $\mathrm{A}$, we see that in fact the estimated effect of relative cohort size on unemployment rates becomes more positive, consistent with endogeneity bias, and is now statistically significant. Also consistent with endogeneity bias, in the second row the estimated coefficient of relative cohort size in the specification for the youth employment rate falls, although it remains positive (and becomes insignificant). 
In Panel B of Table 3, we instrument using the lagged births variable only. On theoretical grounds, lagged births (only) is a better instrument for relative cohort size because it should not be affected by endogenous migration decisions of either adults (or youths). The results are qualitatively consistent with those in Panel A, although the effects of instrumenting are more profound. The estimated effect of relative cohort size on youth unemployment becomes stronger, while the estimated effect on youth employment becomes negative, although it is insignificant. ${ }^{20}$

Although the Hausman tests tend not to lead to rejection of the exogeneity of relative cohort size, the results of instrumenting are qualitatively different, with little increase in the standard errors. Thus, we maintain the IV estimation in the following analyses. In our view, the lagged birth instrument is theoretically superior to the ratio of lagged births to the adult population (reflected also, perhaps, in the lower p-values, between .10 and .15 , from the Hausman test). Thus, we retain this instrument in the following tables.

Overall, consideration of the endogeneity of relative cohort size leads to stronger evidence of cohort crowding effects on youth unemployment. In addition, it eliminates the anomalous positive effect of relative cohort size on the youth employment rate.

\section{Alternative Aggregate Demand Controls}

In Table 4 we explore the sensitivity of our results to using a measure of the business cycle that is more exogenous with respect to labor market developments. After all, given some substitutability between younger and older workers, adult employment and unemployment rates may be affected by youth population shares. In addition, other factors may affect youth employment or unemployment, which in turn may affect adult employment or unemployment, although the endogeneity bias could probably go in either direction. ${ }^{21}$ We therefore instead use the lagged growth rate of GNP (which was more strongly related to youth employment and 
unemployment rates than was the contemporaneous growth rate, consistent with unemployment and employment being lagging indicators). The results are reported in Panel A.

The estimated effects of lagged GNP growth are consistent with expectations, as it has a negative effect on youth unemployment rates, and a positive effect on youth employment rates. In the equation for youth unemployment rates, the estimated effect of relative cohort size more than doubles, to 1.12 , and remains statistically significant, while the estimated effect of relative cohort size on youth employment rates remains negative, but small and insignificant. In Panel B, we include the adult employment and unemployment rates, as well as lagged GNP growth. The estimated effect of relative cohort size falls to .6 for youth unemployment, and remains small, negative, and insignificant for youth employment rates. It is not entirely clear which estimates in Table 4 are better. Our sense is that while the adult employment and unemployment measures are prone to endogeneity bias, this bias is likely to be minor, and the bias from omitting variables that affect labor markets but are not be captured by lagged GNP growth may be more severe.

Results Disaggregated by Sex

In Table 5 we reestimate the preferred specification from the preceding analysis separately for men and women. Specifically, in equation (1) our youth unemployment and employment rate variables are now the rates for either young men or young women. We continue to define the relative cohort size variable for men and women together, because (barring war) the fraction of the youth cohort that is one sex or the other is presumably stable over time, and because we do not think that young men and women in the countries included in our sample compete in entirely distinct labor markets. The specification of the aggregate demand controls is perhaps more problematic here. When we use the adult employment and unemployment rates, we use the rates for men and women together, so as not to confound 
different effects of cohort crowding on youth labor markets for men and women with trends or changes in employment or unemployment rates of women. Nonetheless, the adult rates could still have rather different relationships with the youth rates for men and women because of changing trends, rather than because the cycle has different effects. As a consequence, we also estimate specifications using the lagged GNP control to capture cyclical effects.

The results indicate that cohort size effects on young men's unemployment rates are less severe than their effects on young women's unemployment rates. In the specifications using adult employment and unemployment rates as controls, we actually find that only young women's unemployment rates rise in response to a larger youth cohort. In the specifications with the lagged GNP control, there are sizable effects for both young men and young women, although the effect is still considerably larger for women. For neither sex do we find much effect on youth employment rates.

These results suggest that young women bear a disproportionate burden of unemployment when youth cohorts are large. ${ }^{22}$ One interpretation of this result is that employers tend to hire young men first, and turn to young women when supply conditions are tight. Another possibility is that labor markets and marriage markets interact. When cohort size rises, because women tend to marry slightly older men, marriage rates for women may fall, leading to higher labor force participation rates for women which could, in principle at least, raise their unemployment rate but not their employment rate. For men, in contrast, this channel of influence of cohort size would not operate because of the weaker connection between marriage and labor force participation. While we regard the differences by sex as interesting, in the ensuing analysis we continue to look at all young workers together, since from a policy perspective the overall effects of population changes on youth labor markets may be of most interest. But sex differences in cohort crowding effects merit further research. 


\section{Variations in Specifying the Effects of Cohort Crowding}

As discussed earlier, it is possible that the effects of relative cohort size on employment and unemployment of youths vary over the business cycle, with large youth cohorts having a more depressing effect on youth labor markets when overall labor markets are slack. To address this issue, we estimate augmented specifications of the form

$$
Y E_{i t}=R C S_{i t} \beta+A E_{i t} \gamma+R C S_{i t} \cdot A E_{i t} \gamma^{\prime}+D_{i t} \delta+\epsilon_{i t},
$$

where the adult unemployment rate is interacted with relative cohort size. The hypothesis is that $\gamma^{\prime}<0$ in the employment rate regressions, so that youth employment rates fall by more in response to a large cohort in a slack labor market, and similarly that $\gamma^{\prime}>0$ in the unemployment rate regressions.

The results for equation (2) are reported in Table $6 .^{23}$ Although the estimated coefficients of the population share/adult unemployment rate interactions are statistically significant (at the five- or ten-percent level) for both the unemployment and employment rate regressions, the signs are not as expected. For example, the estimates suggest that the effect of a large youth cohort in raising youth unemployment is lower when adult unemployment is high. (Note that this does not imply that youth unemployment is lower, because a higher adult unemployment rate is also associated with higher youth unemployment.) One possible interpretation of this finding is that periods of high unemployment generally are characterized by high rates of job destruction (Davis, et al., 1996), which leads to relatively more openings

for young workers to be hired than would otherwise be the case..$^{24}$

\section{Incorporating Enrollment Rates}

Earlier, we discussed the potential confounding influence of changes in school enrollment rates, noting that there was evidence that youth enrollment rates rose the most in 
countries with sharp declines in youth employment rates, and raising the possibility that exogenous changes in factors influencing enrollment rates help explain the failure of the results for youth employment rates to conform to the cohort crowding hypothesis.

Table 7 touches briefly on this evidence in the regression context, reporting estimates of our preferred specifications for the countries and years for which the enrollment data are available, and then adding the enrollment rate as a control. ${ }^{25}$ The evidence in Table 7 has two important limitations. First, the sample is much smaller, as we lose countries as well as years. This may underlie the differences in the estimated coefficients of the relative cohort size variable in the first two rows of this table, compared with the comparable specifications for the full sample in Table 3; for this subsample, the estimated effects of relative cohort size are insignificant in the regressions for youth unemployment and employment rates, but the evidence is more consistent with an effect primarily on youth employment. Second, because enrollment may be endogenous, and we expect negative endogeneity bias in the coefficient of enrollment, we may overstate the influence of enrollment on employment. Nonetheless, the third and fourth rows of Table 7 indicate that the results are little affected by adding the youth enrollment rate as a control. As expected, its estimated coefficient is negative (and significant at the ten-percent level) in the youth employment equation. But the estimated coefficient of the relative cohort size variable is largely unaffected in both equations. Thus, the intervening influence of changes in youth enrollment rates does not appear to explain the failure of youth employment rates to behave as predicted by the cohort crowding hypothesis.

\section{Interpreting the Estimates}

On the basis of the results presented in this section, it appears that the most reliable estimates of the average effects of relative cohort size on youth unemployment and employment rates are similar to those found in Panel $\mathrm{B}$ of Table 3 . While the estimated employment rate 
elasticity is near zero and insignificant, the unemployment rate elasticity is about .5 . Given the declines in relative youth cohort sizes that are projected to occur in the near future in many of the countries in our sample, an interesting question is how much these demographic changes will contribute to lowering youth unemployment rates. We also noted that adult unemployment rates were considerably higher in recent years than in earlier years for many of the countries in our sample. Since the estimated elasticity of the youth unemployment rate with respect to the adult unemployment rate is high (.7 in Panel B of Table 3), it is instructive to compare the consequences of declining youth cohorts for youth unemployment with the consequences of improved aggregate labor market conditions. We focus on youth unemployment rates because relative cohort size appears to affect these rates, and because, as indicated earlier, youth employment rates may be affected by enrollment decisions.

We present such information in two ways. First, in Figure 12 we atternpt to provide a sense of the relative strength of adult labor market developments and youth cohort size on youth unemployment rates. In the left-hand panel, we show estimated year effects on youth unemployment rates, first with no cyclical or demographic controls, then including a cyclical control, and finally including the relative cohort size variables. ${ }^{26}$ All specifications include year and country dummy variables, and dummy variables for changes in the data series. We define the year effects relative to the overall mean, rather than any specific year, as in Suits (1984). For the youth unemployment rate, with no controls the year effects reflect increases in youth unemployment rates in the early to mid-1980s, and again in the early 1990s. When the adult unemployment rate is included as a control, the pattern changes somewhat. In particular, the year effects display more persistently high youth unemployment rates during the 1980s, presumably revealing more of the effects of large youth cohorts. In the early 1990s, the positive year effects are eliminated, because adult and youth unemployment rates rose sharply 
together in many countries. Finally, when the relative cohort size variable is included, most year effects diminish further, suggesting that large youth cohorts raised youth unemployment rates in these years. However, most of the year effects remain, indicating that cohort size effects account for only part of the movements in youth unemployment rates that are common across countries.

The right-hand panel of Figure 12 shows the estimated country effects from the same specification. Relative youth cohort size explains relatively little of the persistent crosscountry differences in youth unemployment rates. In contrast, for many countries the estimated country effect shrinks considerably once the cyclical control is included.

These results suggest that while declining youth cohorts may hold the promise of improved youth labor markets in the future, any such benefits are likely to pale in comparison to the benefits that might accrue from improved labor markets for all workers. Of course, this conclusion could be affected by the fact that in Figure 12 we first include the adult unemployment rate, and then look at the incremental effect of adding relative youth cohort size; however, if we include the relative youth cohort size variable first, the conclusion is unchanged. To make this point in a simpler fashion, we next report projections of future youth unemployment rates, based on projected youth cohort sizes and alternative scenarios regarding future adult unemployment rates.

Projecting relative cohort size is easy, because youth cohorts that will enter the labor market in the next 16 years have already been born, although immigration and other influences can intervene. The future course of the adult unemployment rate is more uncertain. We therefore present three simple scenarios: 1) that adult unemployment rates in each country will remain at their mean for the 1990-1994 period (the most pessimistic scenario for almost all countries), 2) that adult unemployment rates will revert to their means computed over the 
entire sample period, and 3) that adult unemployment rates will return to their means for the 1975-1980 period (the most optimistic scenario for almost all countries). We regard the first and third scenarios as providing plausible bounds on the future course of adult unemployment rates. ${ }^{27}$

Figure 13 displays the projections for each country. In each figure, the solid line is the projection of relative youth cohort size (we show the projections for the years 2000,2005 , and 2010). ${ }^{28}$ The other three lines are the projected youth unemployment rates for each of the three adult unemployment rate scenarios. The figure indicates much bigger changes in youth unemployment rates associated with changes in adult unemployment rates over the range seen in the last two decades, than with the projected changes in youth shares over the next 10-15 years. Spain and Italy provide relatively extreme illustrations of this point. In Spain, the range of variation in future youth unemployment rates given alternative scenarios regarding the adult unemployment rate is much greater than that associated with the sharp projected decline in the youth share. In Italy, the persistence of recent high adult unemployment rates would completely offset the beneficial effects of sharply declining youth cohorts.

The greater importance of differences in the level of aggregate economic activity is partly due to the higher estimated elasticity of the youth unemployment rate with respect to the adult unemployment rate than with respect to relative cohort size (in Panel B of Table 3). It is also partly due to the fact that the range of variation in adult unemployment rates is much larger than that of projected youth shares; that is, even though youth shares are projected to decline in many countries, the declines are too small to produce sharp reductions in youth unemployment rates. Portugal provides a good example, since relative youth cohort size is projected to decline relatively dramatically, but the adult unemployment rate scenarios are very similar. The relatively sharp decline in youth cohort size from about .4 to .28 produces a 
decline in the youth unemployment rate of about two percentage points to about ten percent. Although this change is not negligible, it is small relative to the declines in youth unemployment rates that (in other countries) are associated with declines in adult unemployment rates. Thus, the qualitative conclusion is that improving aggregate labor markets has much more influence on the health of youth labor markets than do even large reductions in relative youth cohort sizes.

\section{The Role of Institutions in the Response of Labor Markets to Demographic Change}

Having explored the consequences of demographic change for youth labor markets, we now turn to the interaction between demographic change and labor market institutions and policy. Specifically, we consider whether the responses of youth employment and unemployment rates to changes in relative cohort size depend on institutional features of labor markets that affect the flexibility of those markets. For example, in a market with relatively inflexible wages, the response of youth unemployment rates and youth employment rates to changes in relative youth cohort sizes should be greater. This hypothesis is of particular interest given recent attempts to increase labor market flexibility, especially in the European countries (see, e.g., Blank and Freeman, 1994).

While centralized wage setting and other institutions and policies that make wages less flexible may make absorption of large youth cohorts more difficult, associated institutions may improve the quality of entry-level labor, so as to offset adverse impacts on firms during baby busts. In particular, countries with more centralized wage setting tend also to have institutions that support worker training (Lynch, 1994). Employers in countries in which institutions that support worker training are weak or lacking may have difficulty finding qualified young workers, particularly during a baby bust. Training may therefore help employers to offset any "numbers loss." Perhaps it is not a coincidence that there appears to be growing interest in 
training institutions in the U.S. at precisely the time when young workers have become more scarce (e.g., Lynch, 1994; U.S. Office of Technology Assessment, 1990).

We begin with rather broad-brush strokes by examining differences in the response to population changes between the European countries and the other countries in our data set. Freeman (1994) details differences between labor markets in Europe and the U.S.; European labor markets are less flexible, in general, being characterized by stronger unions, higher income support for the unemployed, a more generous safety net, and higher mandated nonwage labor costs. ${ }^{29}$ We therefore first estimate a specification similar to equation (2), but allowing for differential effects of population change in Europe, as in

$$
Y E_{i t}=R C S_{i t} \beta+R C S_{i t} \cdot E U R_{i} \beta^{\prime}+A E_{i t} \gamma+A E_{i t} E U R_{i} \gamma^{\prime}+D_{i t} \delta+\epsilon_{i t},
$$

where EUR is a dummy variable for the European countries, and we allow for different responses of youth unemployment and employment rates to the adult rates in the two sets of countries. If the European countries are characterized as having less flexible labor markets, we might expect both a stronger response of youth unemployment rates to large youth cohorts, and a stronger response of employment rates (because wages are less flexible downward).

Results are reported in Panel A of Table 8. For youth unemployment rates and employment rates, the results indicate little difference between the European and non-European countries. For example, the association between large youth cohorts and higher youth unemployment rates is positive and marginally significant for the non-European countries (with a coefficient estimate of .419), and the interaction for the European countries is slightly larger (.169), but not significantly so.

We next attempt to identify some of the institutional characteristics of labor markets that might underlie the differences between the European and non-European countries. It 
seems appropriate to classify countries with respect to two characteristics that may affect labor market adjustments to population change. The first is the centralization of wage setting, which is thought to be inversely related to the flexibility of wages (e.g., Bruno and Sachs, 1985). Of course, centralization or lack thereof may have more to do with the flexibility of aggregate wage levels than with the flexibility of wages for workers in particular age groups or skill categories. The second institutional characteristic is labor market policies that may inhibit wage adjustments and the reallocation of labor, such as the support given to unemployed or non-employed workers. For example, Burtless (1987) argues that higher unemployment rates in Germany (and other European countries) are attributable to more generous unemployment compensation that allows workers to be more selective about the jobs they take.

The industrial relations literature provides classifications of countries according to the degree of centralization, three of which we use here (Crouch, 1985; Blyth, 1977; and Calmfors and Driffill, 1988). ${ }^{30}$ The first of these classifies countries as corporatist vs. non-corporatist (with the former implying centralization), and the latter two as having high, medium, or low centralization. The countries in our data set that are classified as highly centralized according to all three of these classifications are Norway and Sweden, while Germany and Finland are classified as highly centralized according to two of the three classifications. In all three classifications, the U.K., the U.S., Japan, Canada, and Italy are classified as having a low degree of centralization. ${ }^{31,32}$

Our empirical strategy is to compare the responsiveness of youth unemployment and employment rates to population changes in these two subsets of countries. However, there are a few reasons to be cautious about the relationship between centralization and the response of labor markets to demographic change. First, other institutional features of labor markets may offset the effects of wage rigidity. For example, Leigh (1995) suggests that the Trade Union 
Confederation in Sweden sought centralized wage bargaining with wage equalization across industries and regions, but also encouraged active labor market policies to increase employability of workers at prevailing wages. ${ }^{33}$ Second, labor market flexibility may change over time. For example, labor markets in the U.K. increased in flexibility with some of the reforms introduced after 1979 (Cappelli, 1993), and Blank and Freeman (1994) describe numerous changes implemented in European countries to attempt to increase labor market flexibility in the 1980s. Third, a priori classifications of countries based upon centralization of labor markets may not always be reflected in actual wage adjustments across skill groups, etc. (Card, et al., 1996). ${ }^{34}$

We estimate an augmented version of equation (3) of the form

$$
Y E_{i t}=R C S_{i t} \beta+R C S_{i t} \cdot H_{i} \beta^{\prime}+R C S_{i t} \cdot M_{i} \cdot \beta^{\prime \prime}+A E_{i t} \gamma+A E_{i t} \gamma \cdot H_{i} \cdot \gamma^{\prime}+A E_{i t} \gamma \cdot M_{i} \cdot \gamma^{\prime \prime}+D_{i t} \delta+\epsilon_{i t} \text {, }
$$

where $\mathrm{H}$ is a dummy variable set equal to one for those countries classified as having a high degree of centralization, and $\mathrm{M}$ is a dummy variable set equal to one for those countries classified as neither high nor low, so that the reference group is those classified as having a low level of centralization. ${ }^{35}$ The hypothesis is that $\beta^{\prime}$ is positive in the youth unemployment rate regression, and negative in the youth employment rate regression.

Panel B of Table 8 presents the results. The evidence is consistent with centralization leading to considerably stronger positive effects of large youth cohorts on youth unemployment. The estimated difference in the effect of relative cohort size on youth unemployment, between the countries classified as highly centralized and those classified with low centralization, is large (the estimated coefficient of the interaction is .719) and is statistically significant. Looking at youth employment rates, the estimated coefficient of this interaction is not significant, although it is negative as predicted. Thus, the evidence that 
centralization of wage setting leads to larger responses of youth labor markets to population change is relatively strong when the outcome is the youth unemployment rate.

There is a multitude of ways to attempt to classify economies in terms of other features that affect labor market flexibility. We focus in particular on the support provided to the ablebodied non-employed, which should be related to the degree to which fluctuations in cohort size elicit market clearing wage movements. In particular, we follow Layard, et al. (1991) in classifying countries according to whether they provide essentially indefinite support to these individuals (through a combination of unemployment insurance, supplemental benefits, and means-tested programs). The list of countries in our data set that do so includes: Germany, Ireland, the Netherlands, the U.K., Australia, and Finland. ${ }^{36}$ Because this list of countries is quite different from the list of countries with highly centralized wage setting, we obtain independent information. We estimate a specification of the form

$$
Y E_{i t}=\operatorname{RCS}_{i t} \beta+\operatorname{RCS}_{i t} \cdot I_{i} \beta^{\prime}+A E_{i t} \gamma+A E_{i t} \cdot I_{i} \gamma^{\prime}+D_{i t} \delta+\epsilon_{i t}
$$

where $\mathbf{I}$ is a dummy variable set equal to one for those countries with indefinite support. The hypothesis is that $\beta^{\prime}$ is positive in the youth unemployment rate regression, and negative in the youth employment rate regression.

The results, reported in Panel $\mathrm{C}$ of Table 8, are somewhat supportive of this hypothesis, as the signs of the estimates of $\beta^{\prime}$ are consistent with expectations, but only the estimated coefficient in the youth employment rate regression (-.206) is marginally significant.

To summarize, there is little evidence that European labor markets in general have sharper responses of youth employment and unemployment to fluctuations in the size of youth cohorts. ${ }^{37}$ The results suggest that centralized wage-setting institutions, and possibly greater support given to the unemployed, may inhibit absorption of large entering cohorts. However, 
the evidence is rather weak statistically, and is based on relationships estimated at the aggregate level that clearly need to be explored at other levels as well.

Ironically, because flexible wages tend to dampen the response of youth unemployment rates to fluctuations in the size of youth cohorts, increasing wage flexibility should not be viewed as a tool to help exploit the projected declines in youth population shares in order to reduce youth unemployment rates over the next 10-15 years; increased flexibility may directly reduce unemployment of youths and adults, but it weakens the relationship between cohort size and youth unemployment. ${ }^{38}$

\section{$\underline{\text { V. Conclusions }}$}

In this paper we report evidence from a cross-national study of the effects of cohort crowding on youth unemployment and employment, using data on most of the OECD countries from 1970 to 1994 . The use of data from many countries, with a relatively long panel, offers advantages relative to the existing literature for reducing the influence of period and other cohort effects, and for avoiding faulty inferences from strongly trended data. In addition, we consider a number of issues not addressed in earlier studies, including the potential endogeneity of relative cohort size measures, augmentation of the model to allow for variation in the effects of cohort size over the business cycle, and the influence of labor market institutions on the response of youth labor markets to demographic change. Our preferred estimates indicate that the response of youth employment rates to relative youth cohort size is close to zero. But they indicate an elasticity of youth unemployment rates with respect to relative youth cohort size on the order of 0.5 .

We use our estimates to project the likely course of relative youth unemployment rates, since the model estimates suggest that projected declining youth population shares in at least some of the countries in our sample should lead to lower unemployment rates for youths. All 
in all, the lessons from the projection exercises are fairly clear: falling youth population shares should improve youth labor market outcomes over the next 10-15 years in some countries-particularly those with relatively high youth unemployment rates in which large declines in youth population shares are projected (Ireland, Italy, Spain, and Portugal). But even for these countries, and even with an optimistic scenario regarding future adult unemployment rates, the projections never indicate a return to the lower youth unemployment rates seen in the 1970s. Youth unemployment rates are much more responsive to general labor market improvements than to declines in cohort size. In particular, in many countries a return to the tighter labor markets that produced the low adult unemployment rates of the 1970s and 1980s would do far more to improve youth labor markets. Thus, while changes in population age structure may yield some improvements in youth labor markets in some countries, more substantial reductions in youth unemployment will have to be generated from other sources.

One source of improved youth labor markets over the long term may be institutional changes, especially in European labor markets, that will increase flexibility, allowing cohort fluctuations to have greater wage effects and hence smaller employment and unemployment effects. The evidence, while not strong, suggests that greater centralization of wage setting in some European labor markets, and generous support for the unemployed, may increase the response of youth unemployment and employment rates to cohort size fluctuations. However, while increased flexibility may have advantageous direct effects on youth unemployment or the labor market more generally, it does not offer any particular advantage in exploiting future declines in youth population shares. Again, improvements in aggregate labor market performance offer the principal means of reducing youth unemployment rates. Whether these aggregate improvements can be more effectively encouraged through supply side (institutional) changes or aggregate demand policies remains an open question. 


\section{$\underline{\text { Notes }}$}

1. The eleven European countries are Finland, France, Germany, Ireland, Italy, the Netherlands, Norway, Portugal, Spain, Sweden, and the U.K. These averages are estimated using the first and last observation available on each country in the sample period, which are not always in 1970 and 1994, as explained below. We also use data on the U.S., Canada, Australia, and Japan.

2. OECD (1980) presents separate models for 10 countries.

3. A more detailed discussion of these studies is provided in the appendix.

4. The exceptions are: former West Germany: 1970-1993; Ireland: 1971, 1975, 1977, 1979, 1981, 1983-1993; Italy: 1970-1993; Netherlands: 1971-1994; Norway: 1978-1994; Portugal: 1974-1993; Spain: 1972-1994; and the U.K.: 1973, 1975-1977, 1980-1994. We also have much more limited data on youth enrollment rates, discussed below.

5. The unemployment rates appear to be standardized unemployment rates. Leigh (1995, Table 2.4) provides some comparisons of alternative unemployment rate measures across some of the countries in our sample.

6. We use a relatively young cutoff to avoid the influence of changes in retirement policy or behavior that might have substantial effects on 55-64 year-olds. However, the results were not sensitive to using a wider age range.

7. The remaining countries have data as follows: Ireland: 1985-1993; Norway: 1980-1993; Portugal: 1976-1993; and the United Kingdom: 1977, 1982-1993.

8. The estimation of lagged births is best illustrated by an example. We are interested in knowing how many 16-to-24 year-olds in 1970 were born in the U.S. Births 16-to-24 years earlier (in the period 1946-1954) will not include respondents who were born in 1945 but have not yet reached their birthday (and so are still 24). Similarly, this method would include some of the people born in 1954 who have not turned 16 by the survey date. In the absence of information about the date of birth and survey date, we use the expected value of these dates (July 1) and so include one half of 1945 births and exclude one half of 1954 births. The age ranges for lagged births are chosen to match the age ranges in the population and employment data (which, as noted above, vary slightly across countries).

9. These data were constructed by the OECD and supplied to us by Danny Blanchflower and Richard Freeman. For eight countries, actual enrollment rates for 16-24 year-olds are available. For these countries and three additional ones, enrollment rates by single-year ages and by sex are available, although we do not have the population weights at this level of disaggregation. We therefore report the average over all 16-24 year-olds of these disaggregated rates, which is equivalent to a fixed-weight enrollment rate. For the eight countries for which the true rates are available, the series are almost identical.

10. These are defined, respectively, as whether relative cohort size grew by .04 or more, fell by .04 or more, or changed by an intermediate amount. In the 1970s, the countries in the "boom" category include Germany, Spain, and the U.K. Those in the "bust" category include Finland, France, the Netherlands, Sweden, and Japan. All others are grouped in the category exhibiting little trend. For the 1980s and early 1990s the boom countries include Japan only, while the bust 
countries include the U.S., Finland, France, Germany, Ireland, the Netherlands, Norway, Portugal, the U.K., Australia, and Canada.

11. Given that we are studying employment and not hours, it is natural to assume that the substitution effect dominates. In a static model, the wage exerts only a substitution effect on the labor force participation decision.

12. One could argue that the implications for unemployment are more ambiguous, because the unemployment rate depends on the decisions of individuals to remain in the labor force. Singell and Lillydahl (1989) provide a summary of this issue and other problems with respect to the measurement and interpretation of youth unemployment rates.

13. Note that once we include the adult rate corresponding to the youth rate on the left-hand side (e.g., the adult unemployment rate on the right-hand side of the equation for the youth unemployment rate), the specification is essentially identical to one in which the dependent variable is the $\log$ of the youth rate relative to the adult rate. In particular, the estimate of $\beta$ is unaffected by the form of the dependent variable used. This follows because the variables are entered in logs. To see this, note that equation (1), when $\mathrm{AE}$ is the log adult unemployment rate, and $\mathrm{RE}$ is the log of the youth unemployment rate relative to the adult unemployment rate, can be written as

$$
R E_{i t}=R C S_{i t} \beta+A E_{i t}(\gamma-1)+D_{i t} \delta+\epsilon_{i t} .
$$

14. For example, the apprenticeship system in Germany is thought to be responsible for the relatively low ratio of youth to adult unemployment in that country (Sorrentino, 1993), and unemployment rates may systematically differ in some countries (such as Sweden) because of active labor market policies or other policy or measurement differences.

15. We also computed estimates with random country effects. The resulting estimates were very similar to the fixed effects estimates. Large changes in the coefficients in going from OLS to random effects indicate that the random effects specification is inappropriate, because the random effects estimator is a weighted average of the within and the between estimator. Thus, although Hausman tests do not reject random effects in favor of fixed effects, we proceed with fixed country effects.

16. In contrast, estimates with random year effects were little different from those in Panel B. Hausman tests reject the random effects specification in favor of fixed effects (in one case the pvalue was .00 , in the other the matrix difference of the variance-covariance matrices was not positive definite).

17. We lose some observations (in addition to the first) because of breaks in the data series. The estimates for the smaller samples--not accounting for serial correlation--were very similar to those for the full sample. For example, for the specification corresponding to the first row of Panel C, the estimate (standard error) of $\beta$ was .329 (.094); for the specification corresponding to the second row, it was $-.127(.050)$.

18. The qualitative results were similar when we instead introduced dynamics by including relative cohort size lagged one year (along with the contemporaneous value), instead of allowing for serial correlation, although the estimates of the individual coefficients were much less precise. In these 
specifications, however, significant serial correlation in the error remained.

19. Other researchers have raised the endogeneity issue and, for example, used population shares rather than labor force shares to measure cohort size. However, population shares are still affected by endogenous migration. We are not aware of other attempts to remedy this problem by using lagged births as an instrument for a relative labor force or relative cohort size variable.

20. In all cases discussed in this section, the F-statistic for the instrument in the first-stage regression was huge, suggesting that small sample biases are unlikely to be a problem (Bound, et al., 1995).

21. For example, a higher minimum wage that reduces employment rates for young workers may increase employment rates for older workers towards whom employers substitute, leading to downward endogeneity bias in the estimated coefficient of the adult employment rate. Conversely, a negative demand shock for firms employing young workers could increase youth unemployment, and via multiplier effects also increase adult unemployment.

22. We obtain this same qualitative result whether or not we instrument for relative cohort size, and whether or not we correct for serial correlation.

23. We instrument by forming the fitted value of the relative cohort size variable, and using this variable and its interaction with the adult unemployment rate as instruments for RCS and its interaction with the adult unemployment rate. This is the method of "internal instruments" (Bowden and Turkington, 1984).

24. This may seem like a contradictory argument, since there is most likely more hiring of young workers in periods of low unemployment. But we are conditioning on the adult unemployment rate, and are therefore referring to a cohort size/unemployment interaction net of the relationship between adult unemployment and youth unemployment.

25. Again, for the eight countries for which unweighted enrollment rates are available, the results were insensitive to using the unweighted rates or the fixed-weight rates.

26. To focus more sharply on demographic change vs. cyclical effects, this analysis is based on a specification that includes only the adult unemployment rate as a control. The results for this specification were very similar to those including the adult employment rate as a control as well.

27. The other issue that arises is the treatment of time trends in youth unemployment rates. The models estimated to this point include year dummy variables. In the absence of information on future trends, we simply project based on the year effect for the last year in the sample; however, as the left-hand panel of Figure 12 shows, this year effect is very close to the sample mean.

28. These were also displayed in Figure 1, although the scale is different in that figure.

29. On the other hand, Allen and Freeman (1995) caution against exaggerating the differences in flexibility. They report some evidence that European labor markets are less flexible, manifested in less frequent movements between employment and unemployment. But they do not find evidence of less sectoral reallocation of labor in European labor markets. They also suggest that European labor markets became more flexible relative to the U.S. in the 1980s, compared with earlier decades. 
30. These are discussed in more detail in Blanchflower and Freeman (1992).

31. The complete classifications are listed in Table 8. Ireland, Portugal, and Spain are not included in these classifications, so they are omitted from the estimation.

32. Blanchflower and Oswald (1994, Chapter 7) review literature that tends to classify the U.S., the U.K., and Italy as economies with low centralization, and Germany and Norway as economies with high centralization. Freeman (1994), Card, et al. (1996), and Leigh (1993), among others, also discuss the flexibility of wages, but do not provide as complete a classification of countries.

33. However, Forslund and Krueger (1994) argue that Sweden's active labor market policies have contributed to higher unemployment.

34. However, Card, et al. compare the U.S. and Canada to France, the latter of which is not generally characterized as highly centralized according to the classifications described above.

35. We do not need to add the dummy variables $H$ and $M$ to the regressions, since they are subsumed in the country dummy variables.

36. For details, see Table 6 and Appendix A1 in Layard, et al. (1991).

37. The results reported in this section are very similar if we do not instrument for the relative cohort size variables.

38. Our evidence does not speak to the direct effects of flexibility on youth unemployment rates, because the various measures of flexibility are country-specific and fixed over time, and hence are indistinguishable from the country dummy variables. Some measure of flexibility that changed over time would be required for this purpose, but the analysis of such changes is beyond the scope of this paper. For evidence on the relationship between labor market flexibility and unemployment, see Layard, et al. (1991). 


\section{$\underline{\text { References }}$}

Allen, Steven G., and Richard B. Freeman. 1995. "Quantitative Flexibility in the U.S. Labor Market." Mimeograph, North Carolina State University.

Blanchflower, David G., and Richard B. Freeman. 1992. "Unionism in the United States and Other Advanced OECD Countries." Industrial Relations 31(1): 56-79.

Blanchflower, David G., and Andrew J. Oswald. 1994. The Wage Curve (Cambridge, MA: The MIT Press).

Blank, Rebecca M., and Richard B. Freeman. 1994. "Evaluating the Connection between Social Protection and Economic Flexibility." In Rebecca M. Blank and Richard B. Freeman, eds. Social Protection vs. Economic Flexibility (Chicago: The University of Chicago Press).

Bloom, David E., Richard B. Freeman, and Sanders Korenman. 1987. "The Labour Market Consequences of Generational Crowding. " European Journal of Population 3: 131-76.

Blyth, C. 1979. "Level of National Bargaining." In Collective Government and National Policies (Paris: OECD).

Borsch-Supan, Axel. 1993. "Comment on Klevmarken." In Paul Johnson and Klaus F. Zimmermann, eds. Labour Markets in an Ageing Europe (Cambridge: Cambridge University Press).

Bound, John, David A. Jaeger, and Regina M. Baker. 1995. "Problems With Instrumental Variables Estimation When the Correlation Between the Instruments and the Endogenous Explanatory Variables is Weak." Journal of the American Statistical Association 90: 443-50.

Bowden, Roger J., and Darrell A. Turkington. 1984. Instrumental Variables (Cambridge, England: Cambridge University Press).

Bruno, Michael, and Jeffrey Sachs. 1985. The Economics of Worldwide Stagflation (Cambridge, MA: Harvard University Press).

Burtless, Gary. 1987. "Jobless Pay and High European Unemployment." In Robert Z. Lawrence and Charles L. Schultze, eds. Barriers to European Growth: A Transatlantic View (Washington, DC: The Brookings Institution), pp. 105-74.

Calmfors, L. and J. Driffill. 1988. "Centralisation of Wage Bargaining and Macroeconomic Performance." Economic Policy 6: 13-61.

Cappelli, Peter. 1993. "British Lessons for School-to-Work Transition Policy in the U.S." EQW Working Paper No. 19, National Center on the Educational Quality of the Workforce, University of Pennsylvania.

Card, David, Francis Kramarz, and Thomas Lemieux. 1996. "Changes in the Relative Structure of Wages and Employment: A Comparison of the United States, Canada, and France." NBER Working Paper No. 5487.

Clark, Kim B., and Lawrence H. Summers. 1982. "The Dynamics of Youth Unemployment." In Richard Freeman and David Wise, eds. The Youth Labor Market Problem: Its Nature, Causes and Consequences (Chicago: University of Chicago Press), pp. 199-235.

Crouch, Colin. 1985. "Conditions for Trade Union Restraint." In Leon N. Lindberg and Charles S. Maier, eds. The Politics of Inflation and Economic Stagflation (Washington, D.C.: The Brookings Institution), pp. 105-39.

Davis, Steven J., John C. Haltiwanger, and Scott Schuh. 1996. Job Creation and Destruction (Cambridge, MA: The MIT Press), Chapter 5. 
Fair, Ray C., and Kathryn M. Dominguez. 1991. "Effects of Changing U.S. Age Distribution on Macroeconomic Equations." American Economic Review 81(5): 1276-1294.

Flaim, Paul O. 1990. "Population Changes, the Baby Boom, and the Unemployment Rate." Monthly Labor Review 113: 3-10.

. 1979. "The Effect of Demographic Change on the Nation's Unemployment

Rate." Monthly Labor Review 102: 13-23.

Flinn, Christopher J. 1993. "The Implications of Cohort Size for Human Capital Investment." In Paul Johnson and Klaus F. Zimmermann, eds. Labour Markets in an Ageing Europe (Cambridge: Cambridge University Press).

Forslund, Anders, and Alan B. Krueger. 1994. "An Evaluation of the Swedish Active Labor Market Policy: New and Received Wisdom." NBER Working Paper No. 4802.

Freeman, Richard B. 1994. "How Labor Fares in Advanced Economies." In Richard B. Freeman, ed. Working Under Different Rules (New York: The Russell Sage Foundation), pp. $1-28$.

Hartog, Joop, Hessel Oosterbeek, and Coen Teulings. 1993. "Age, Wages, and Education in The Netherlands." In Paul Johnson and Klaus F. Zimmermann, eds. Labour Markets in an Ageing Europe (Cambridge: Cambridge University Press).

Klevmarken, N. Anders. 1993. "On Ageing and Earnings." In Paul Johnson and Klaus F. Zimmermann, eds. Labour Markets in an Ageing Europe (Cambridge: Cambridge University Press).

Layard, Richard, Stephen Nickell, and Richard Jackman. 1991. Unemployment: Macroeconomic Performance and the Labour Market (Oxford: Oxford University Press).

Leigh, Duane. 1993. Assisting Workers Displaced by Structural Change (Kalamazoo, W.E. Upjohn Institute for Employment Research).

Levine, Phillip B., and Olivia S. Mitchell. 1988. "The Baby Boom's Legacy: Relative Wages in the Twenty-First Century." American Economic Review 78(2): 66-9.

Lynch, Lisa, ed. 1994. Training and the Private Sector: International Comparisons (Chicago, University of Chicago Press and NBER).

Nardone, Thomas. 1987. "Decline in Youth Population Does Not Lead to Lower

Jobless Rates." Monthly Labor Review 110: 37-41.

Nickell, Stephen. 1993. "Cohort Size Effects on the Wages of Young Men in Britain: 1961-1989." British Journal of Industrial Relations 31(3): 459-69.

OECD. 1980. Youth Unemployment: The Causes and Consequences (OECD: Paris).

Schmidt, Christoph M. 1993. "Ageing and Unemployment." In Paul Johnson and

Klaus F. Zimmermann, eds. Labour Markets in an Ageing Europe (Cambridge: Cambridge University Press).

Singell, Larry D., and Jane H. Lillydahl. 1989. "Some Alternative Definitions of Youth Unemployment: A Means for Improved Understanding and Policy Formation." American Journal of Economics and Sociology 48(4): 457-71.

Sorrentino, Constance. 1993. "International Comparisons of Unemployment Indicators." Monthly Labor Review 116(March): 3-24.

Stapleton, David C., and Douglas J. Young. 1988. "Educational Attainment and Cohort

Size." Journal of Labor Economics 6(3): 330-61.

Suits, Daniel B. 1984. "Dummy Variables: Mechanics V. Interpretation." Review of Economics and Statistics 66: 177-80.

U.S. Office of Technology Assessment. 1990. Worker Training: Competing in the New International Economy (Washington DC, U.S. Government Printing Office), September. 
Wright, Robert E. 1991. "Cohort Size and Earnings in Great Britain. "Journal of Population Economics 4: 295-305.

Zimmermann, Klaus F. 1991. "Ageing and the Labor Market: Age Structure, Cohort Size and Unemployment." Journal of Population Economics 4: 177-200. 

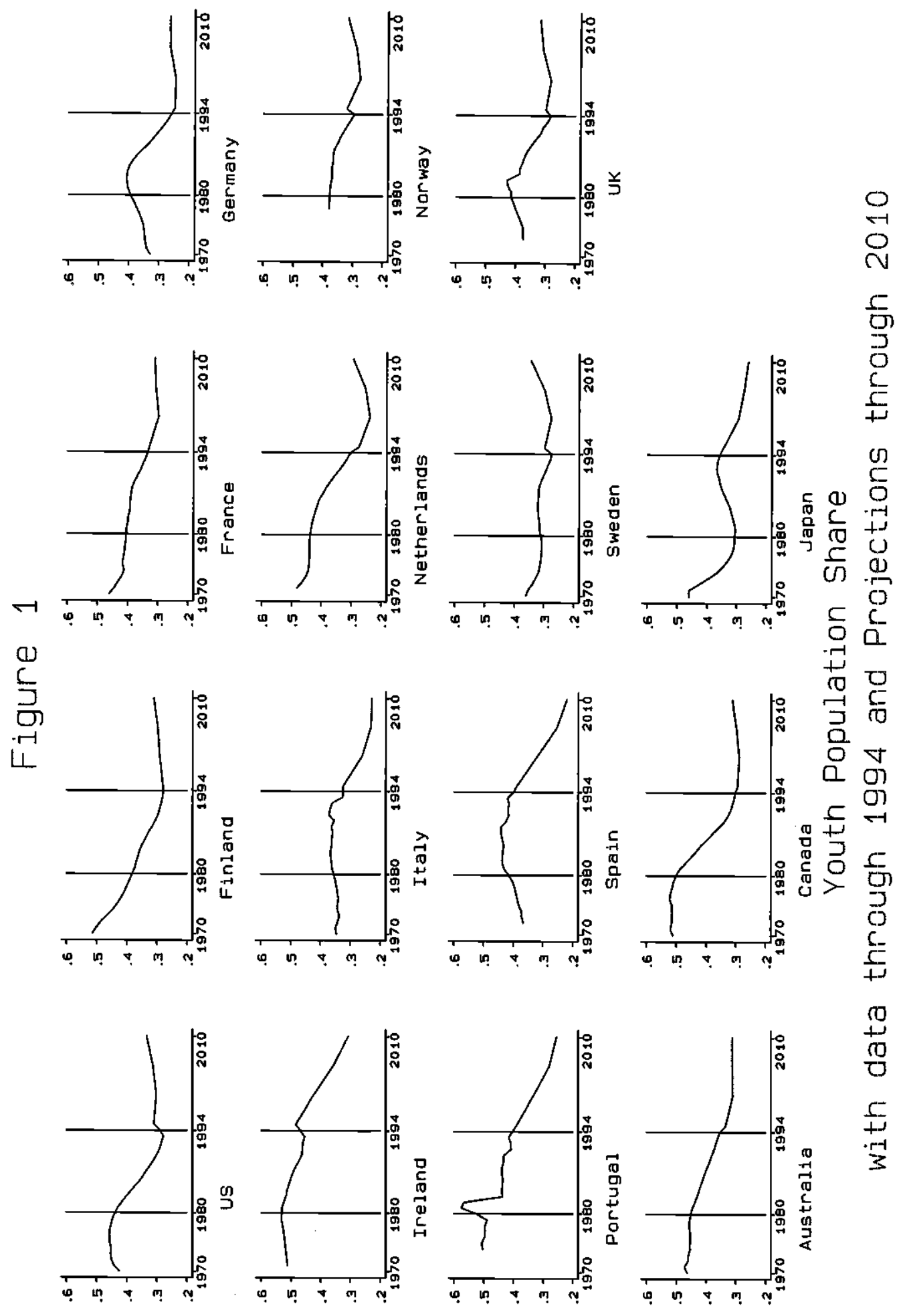

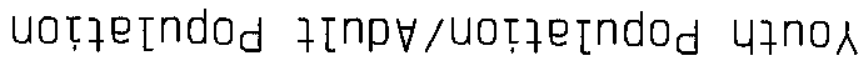




\section{(-) Uoţeindod zinp $/$ /uotiferndod uznox}
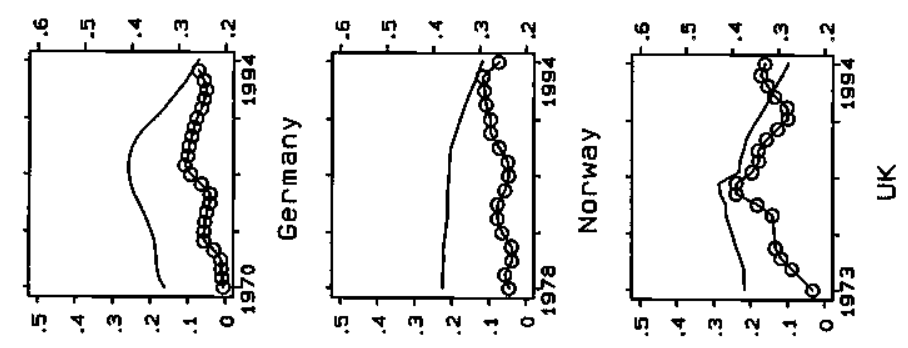

弚

0
0
$C$
$c 0$
$\frac{1}{C D}$

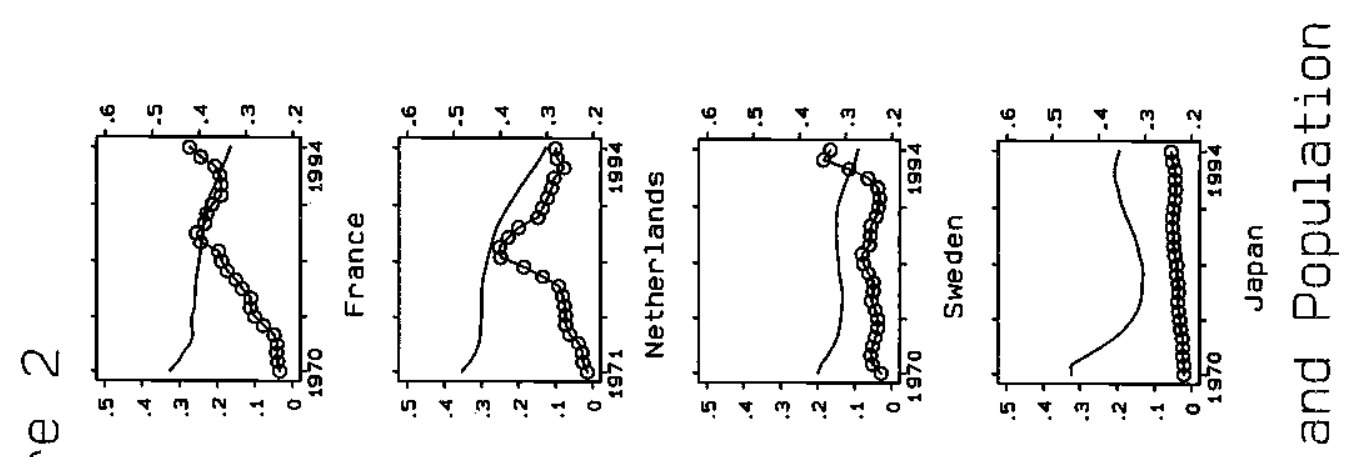

它
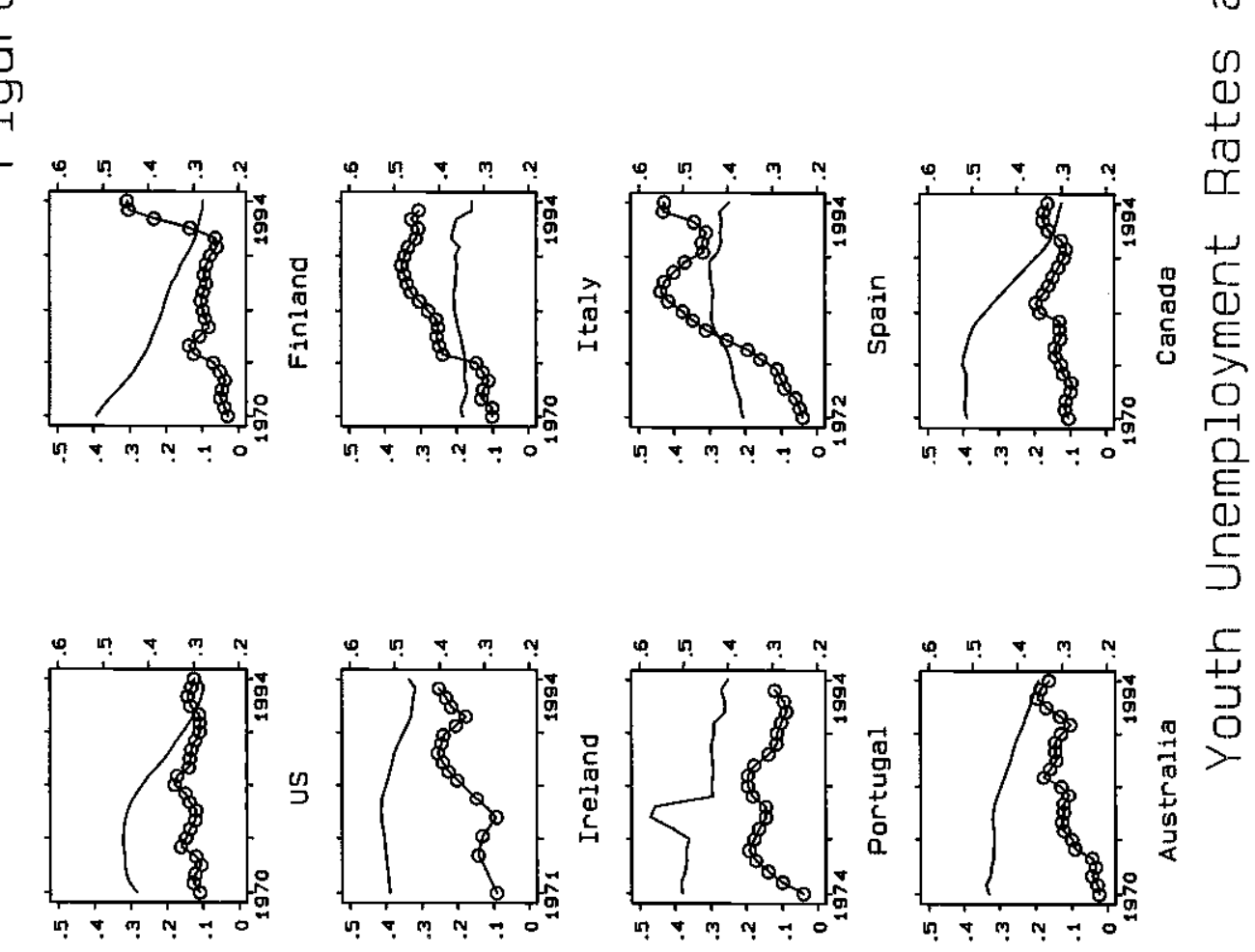

(0) afey zuawkogdmaun ułnos 


\section{(-)Uoţze[ndod zinpH/Uoţe[ndod uzno人}
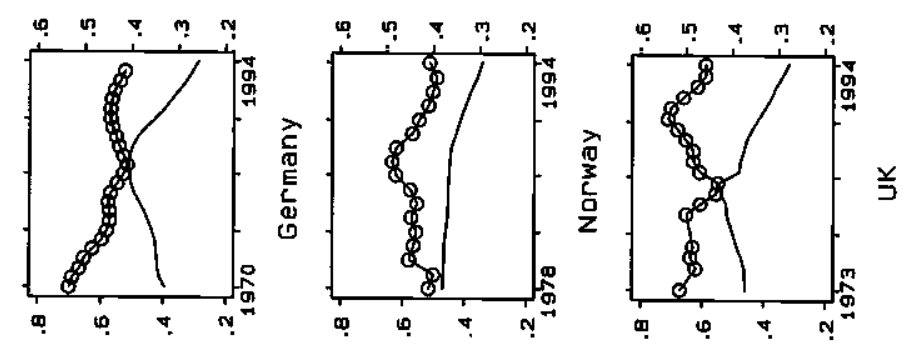

0
0
6
0
$\frac{1}{00}$
$\frac{1}{0}$
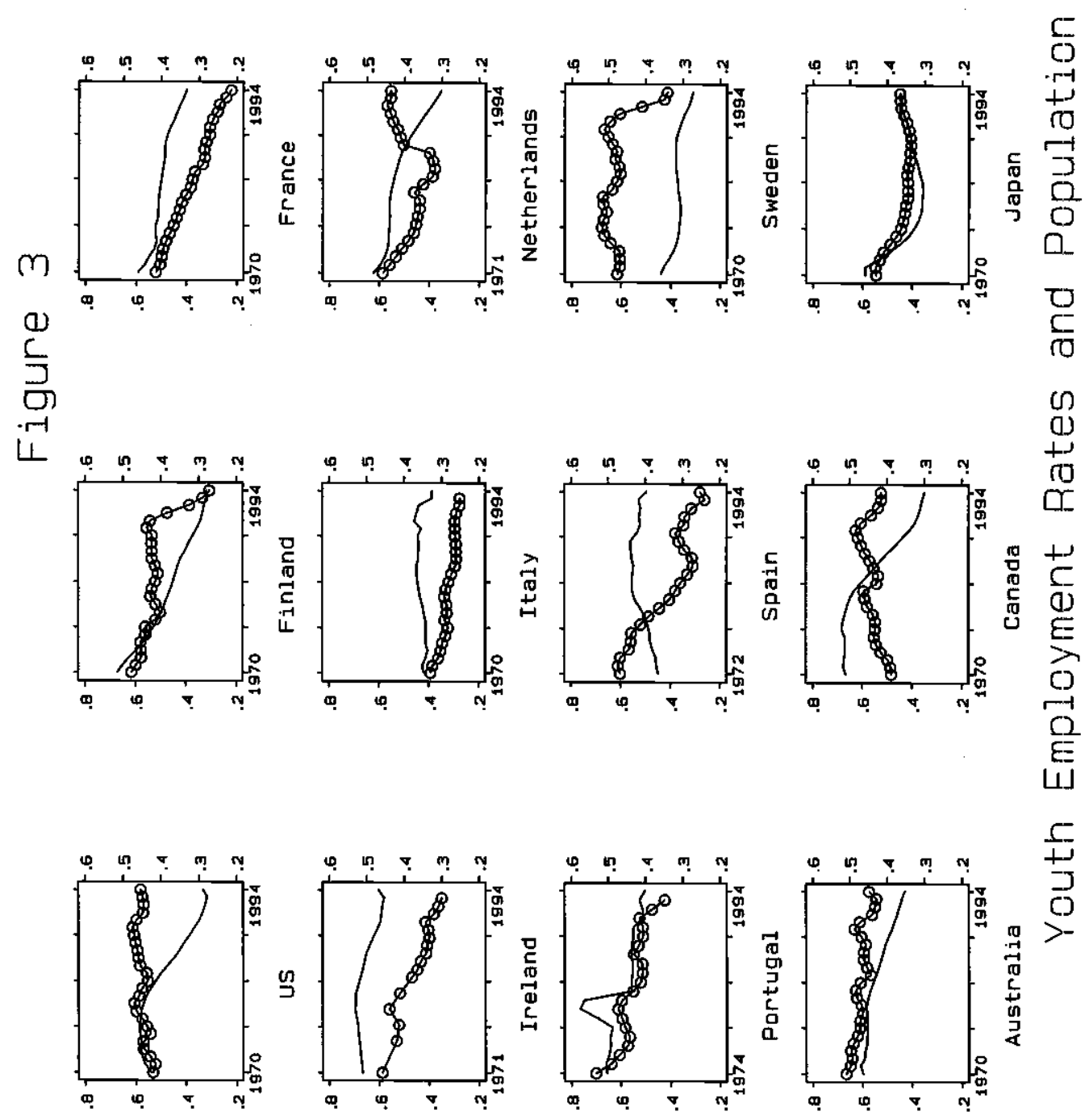

(0) әғеу fuәшко[dm $\exists$ 47nok 


\section{(-)uotzetndod zinp /uotzetndod uzno人}
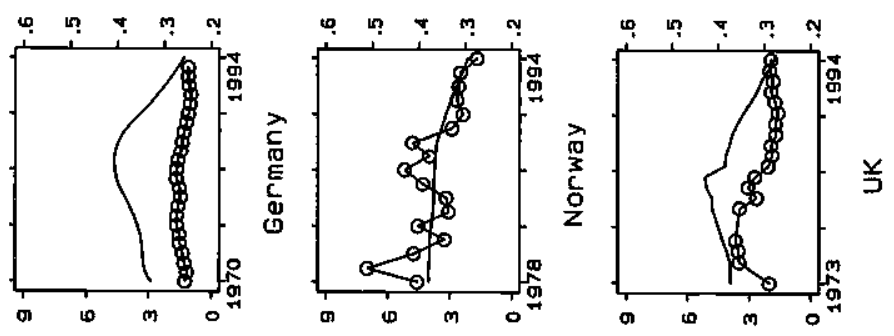

0
0
$c$
$\frac{10}{0}$
$\frac{1}{0}$
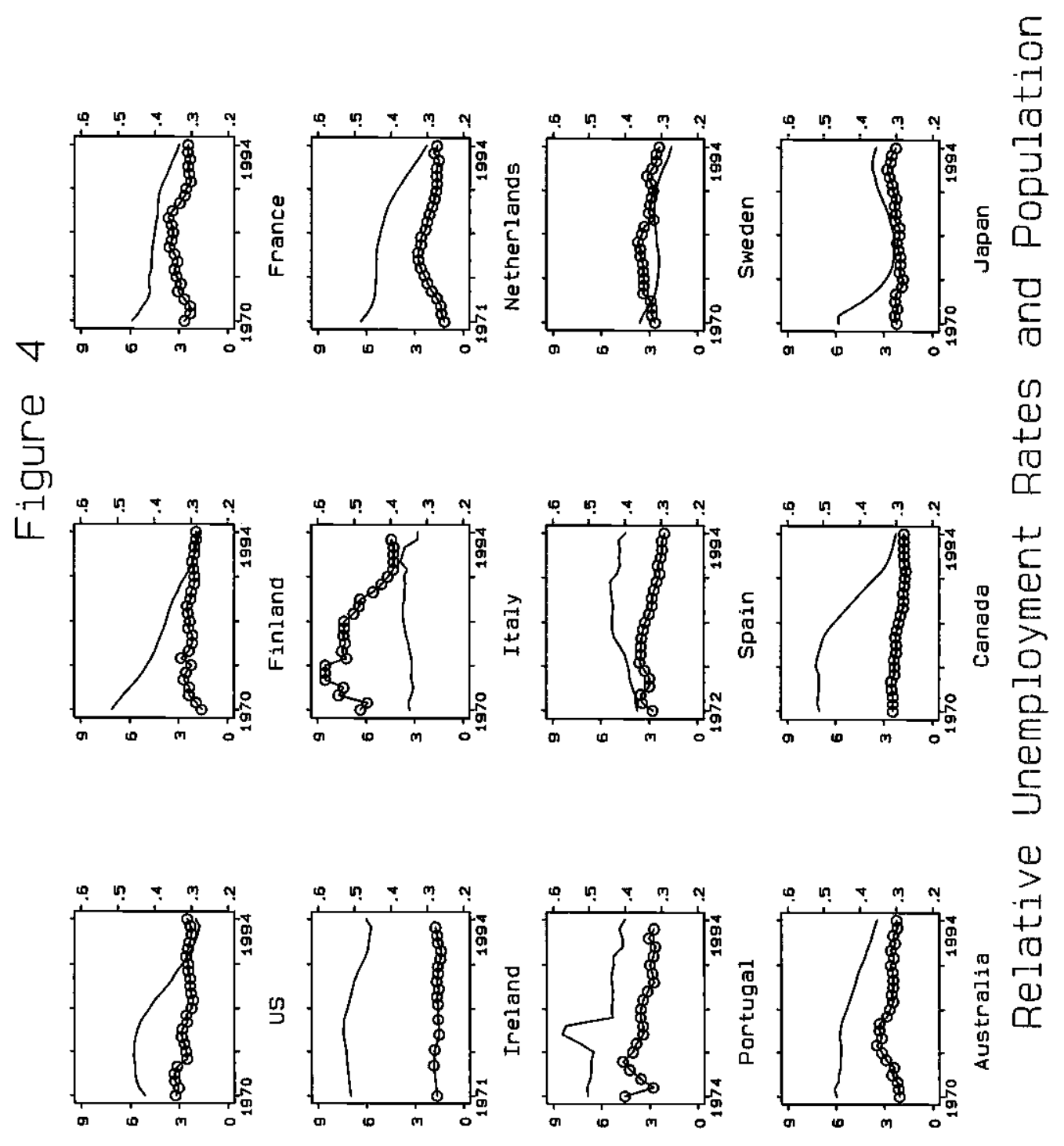

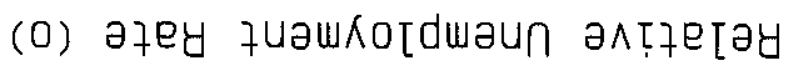


(-)uotzerndod finp $/$ /uotze [ndod uznoN
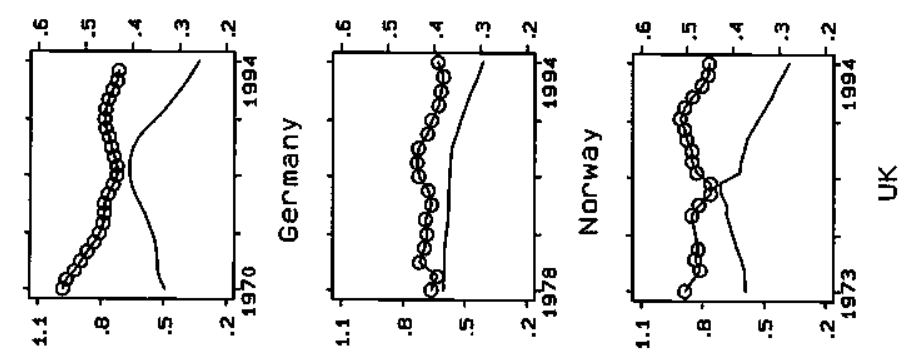

07
0
$c$
0
$\frac{0}{0}$
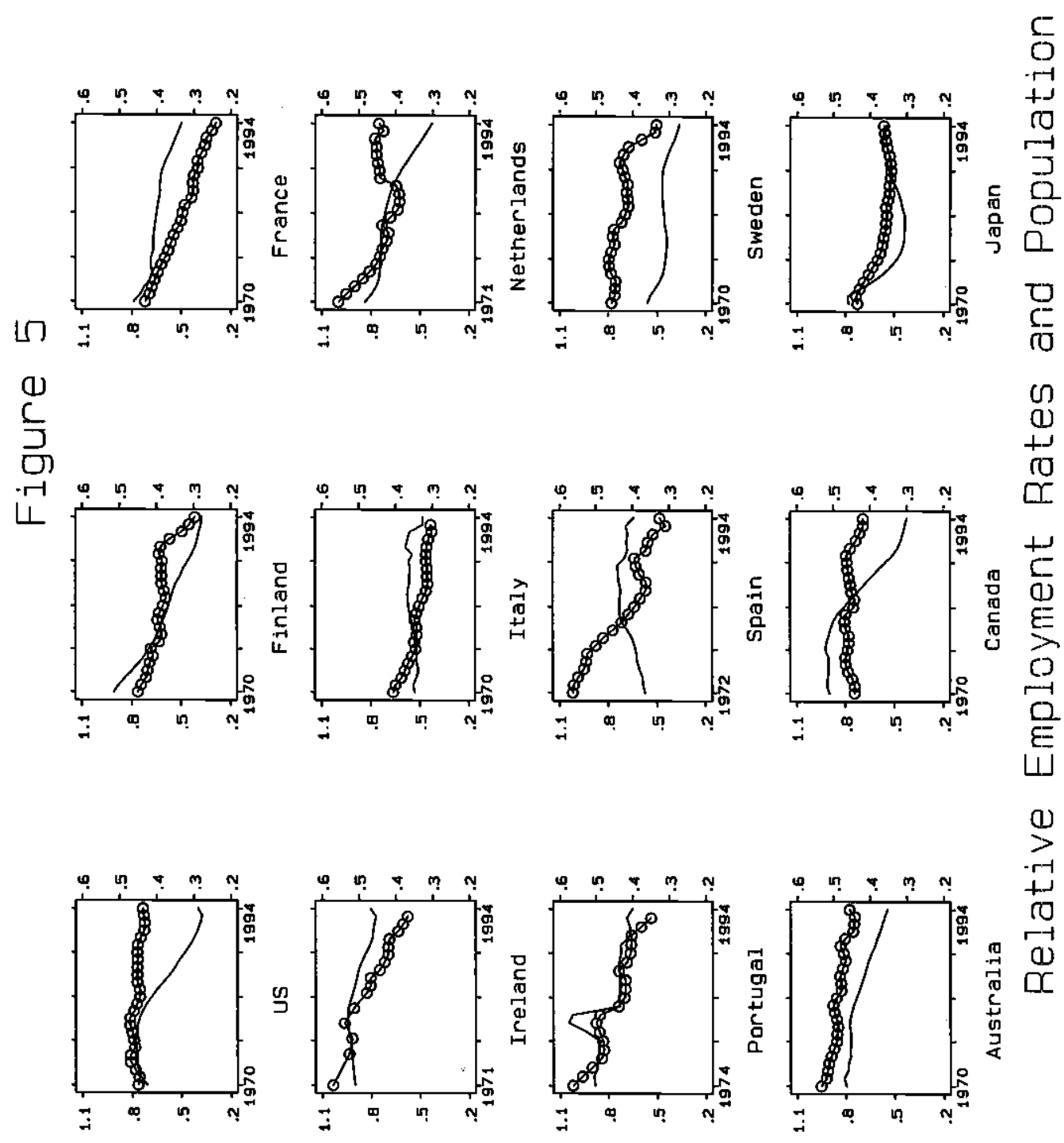

(0) әұеy ұиәшкогdш әлтฺетәу 
(0) әтеу ғиәш[боли

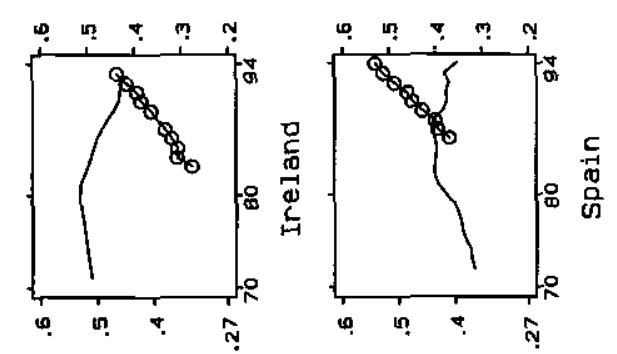

$\frac{0}{0} \frac{0}{c}$

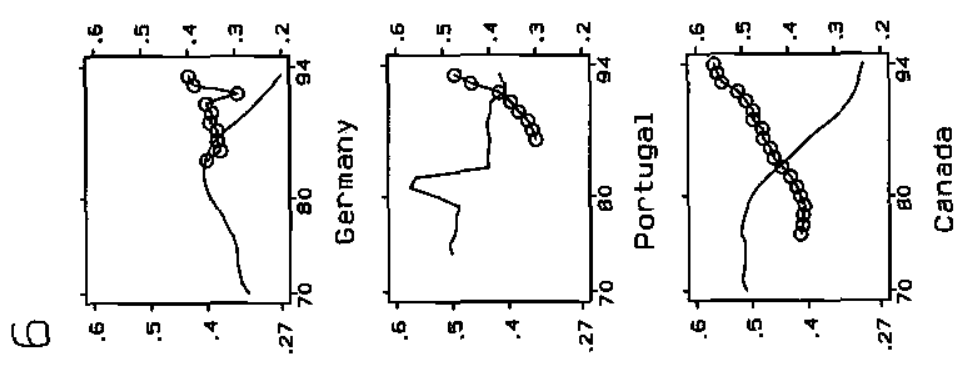

$c$
0
$-r-1$
+0
0
-1
-7
0
0
0

崩
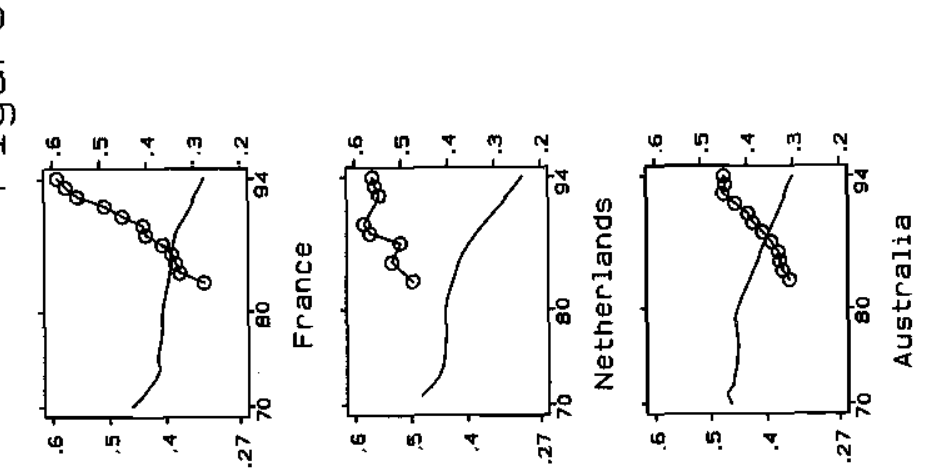

$\frac{0}{0}$

( )

(1)

(c)
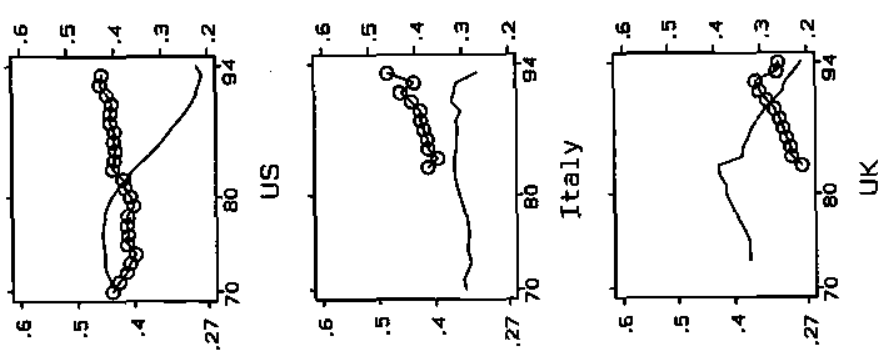

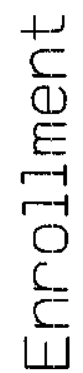

(-) votiferndod zinp $/$ /uotzerndod uznoᄉ 
(0) әғеу диәшт[0งи

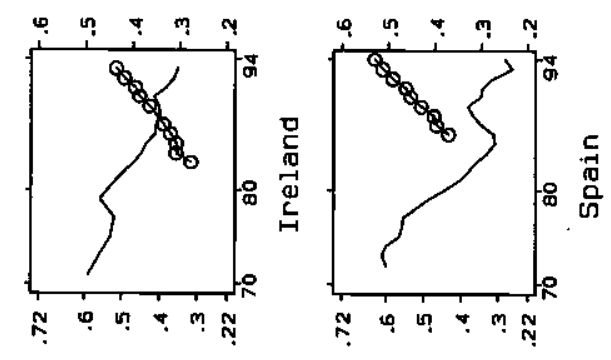

0
0
+0
0

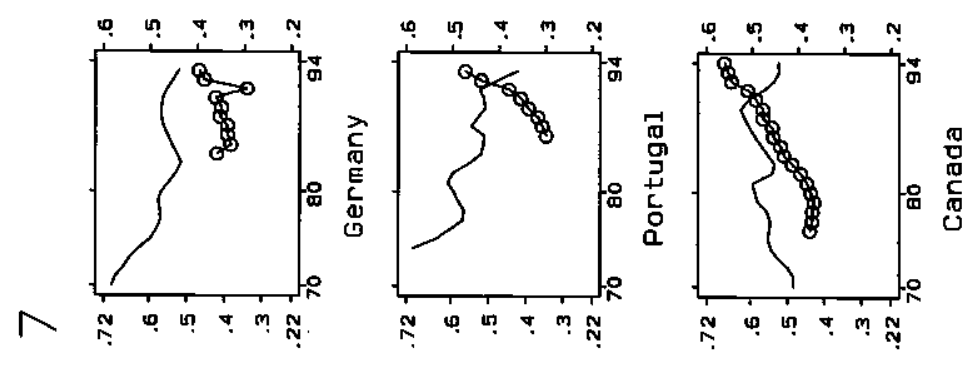

\)

$\frac{1}{0}$
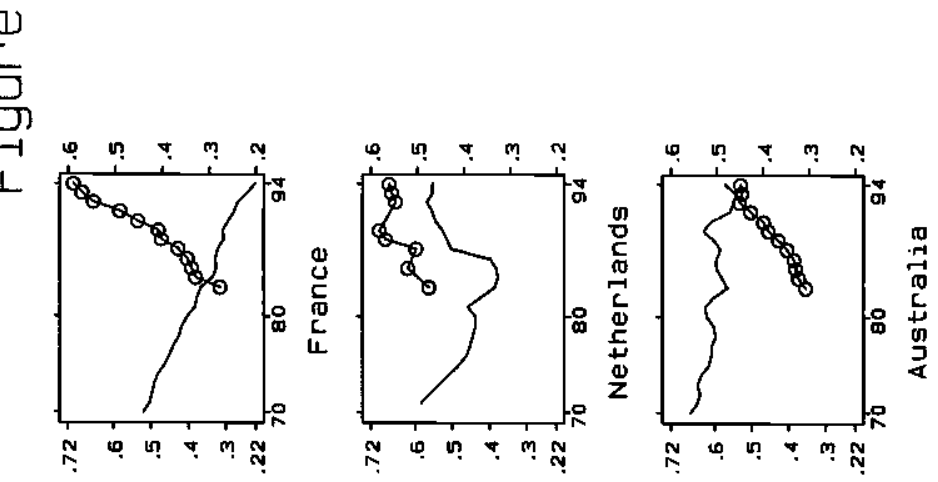

$\frac{\mathrm{T}}{\frac{0}{0}}$

0

(1)

(2)

$\checkmark$

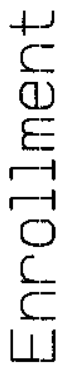
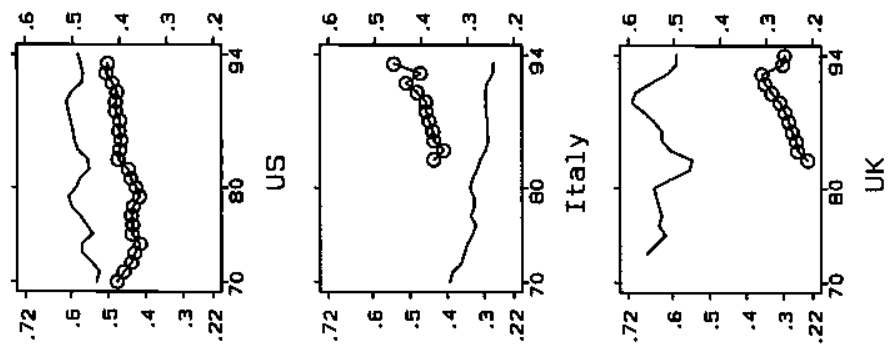

(-) ә7еу ұUәшко[dw $\exists$ 47no人 

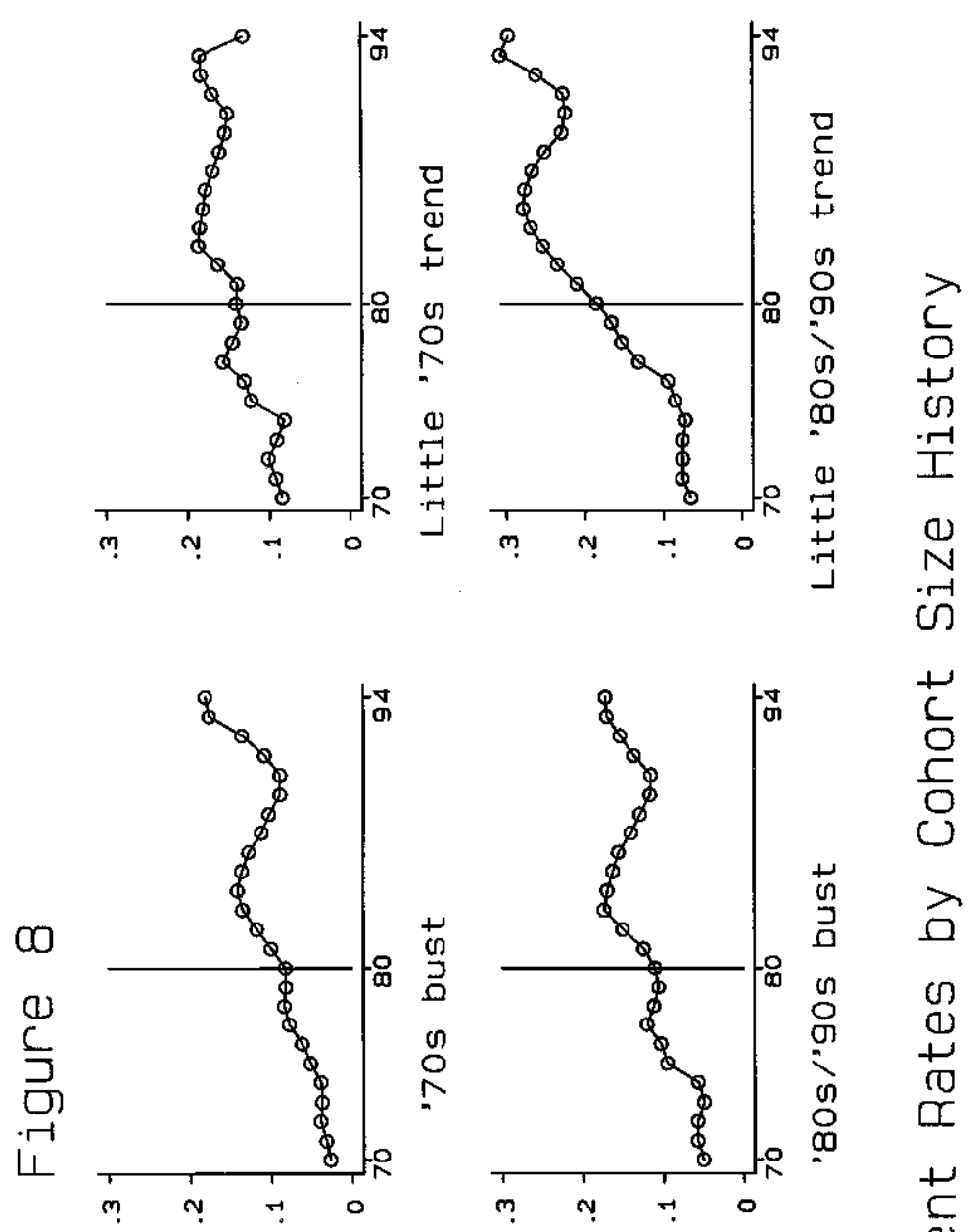

$\frac{1}{0}$

ठ

0
+1
+0
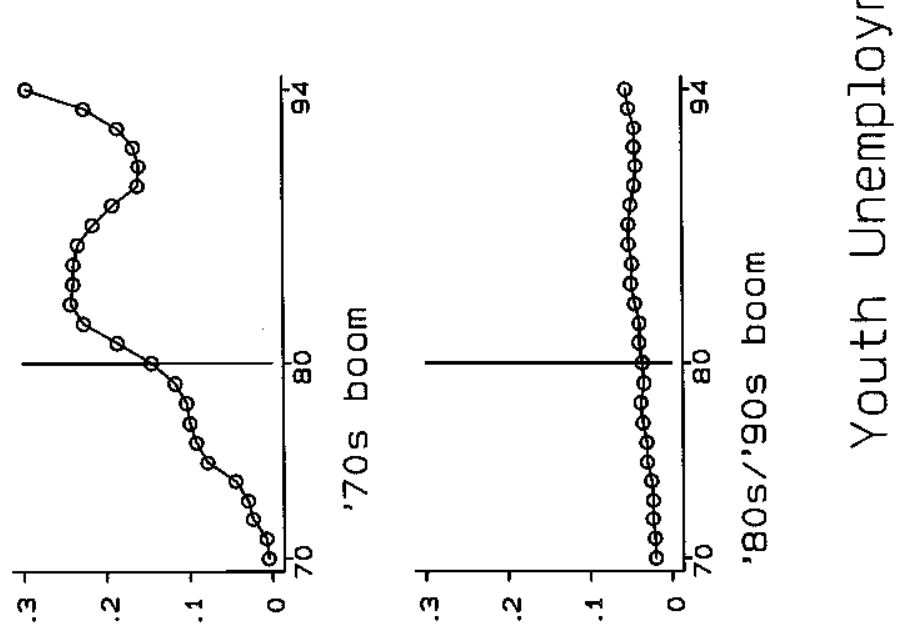

azey quamkotdmaun uzno人 


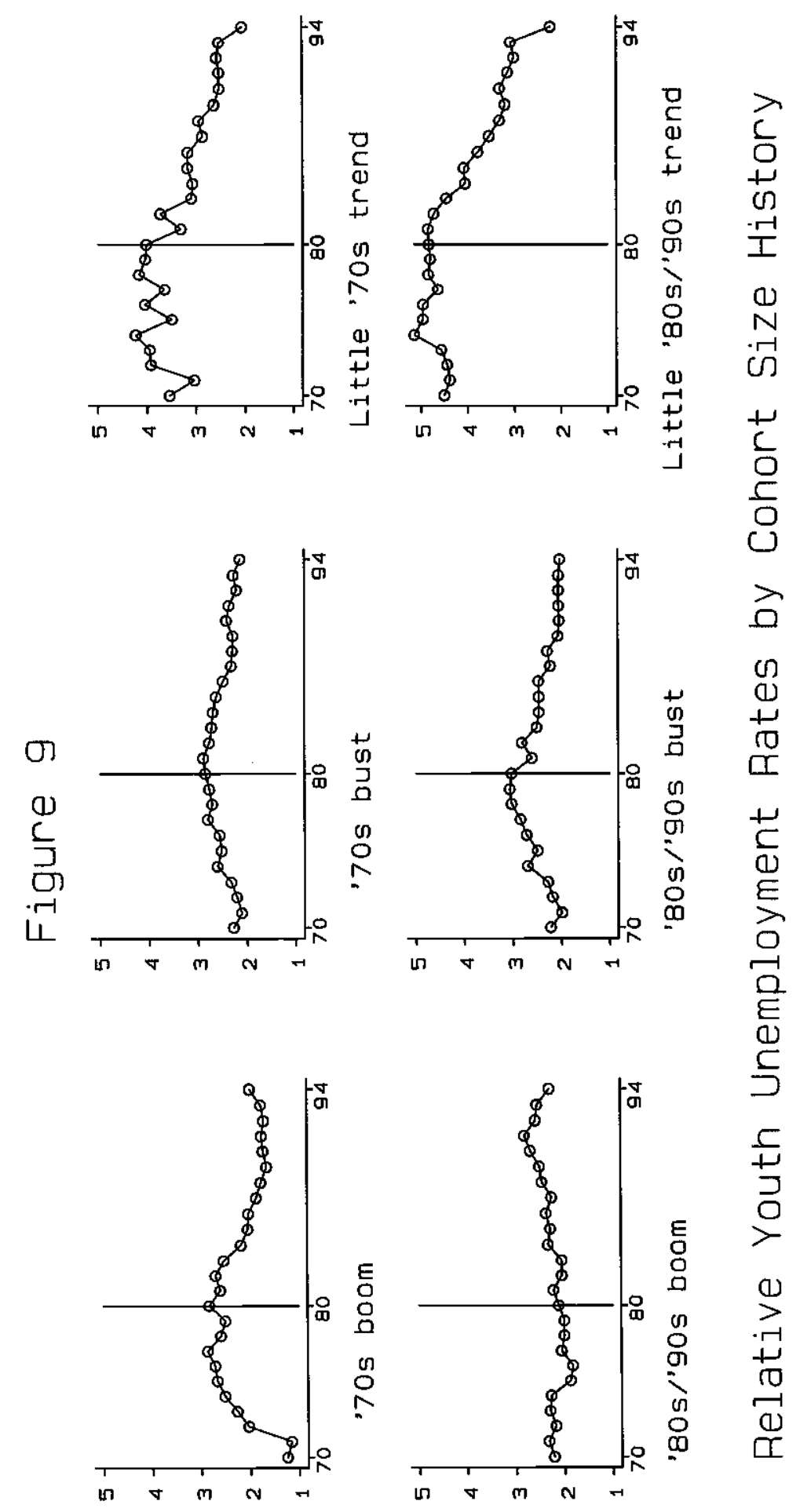

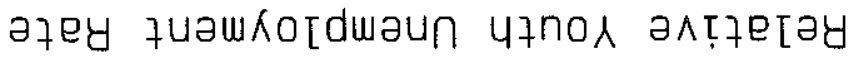



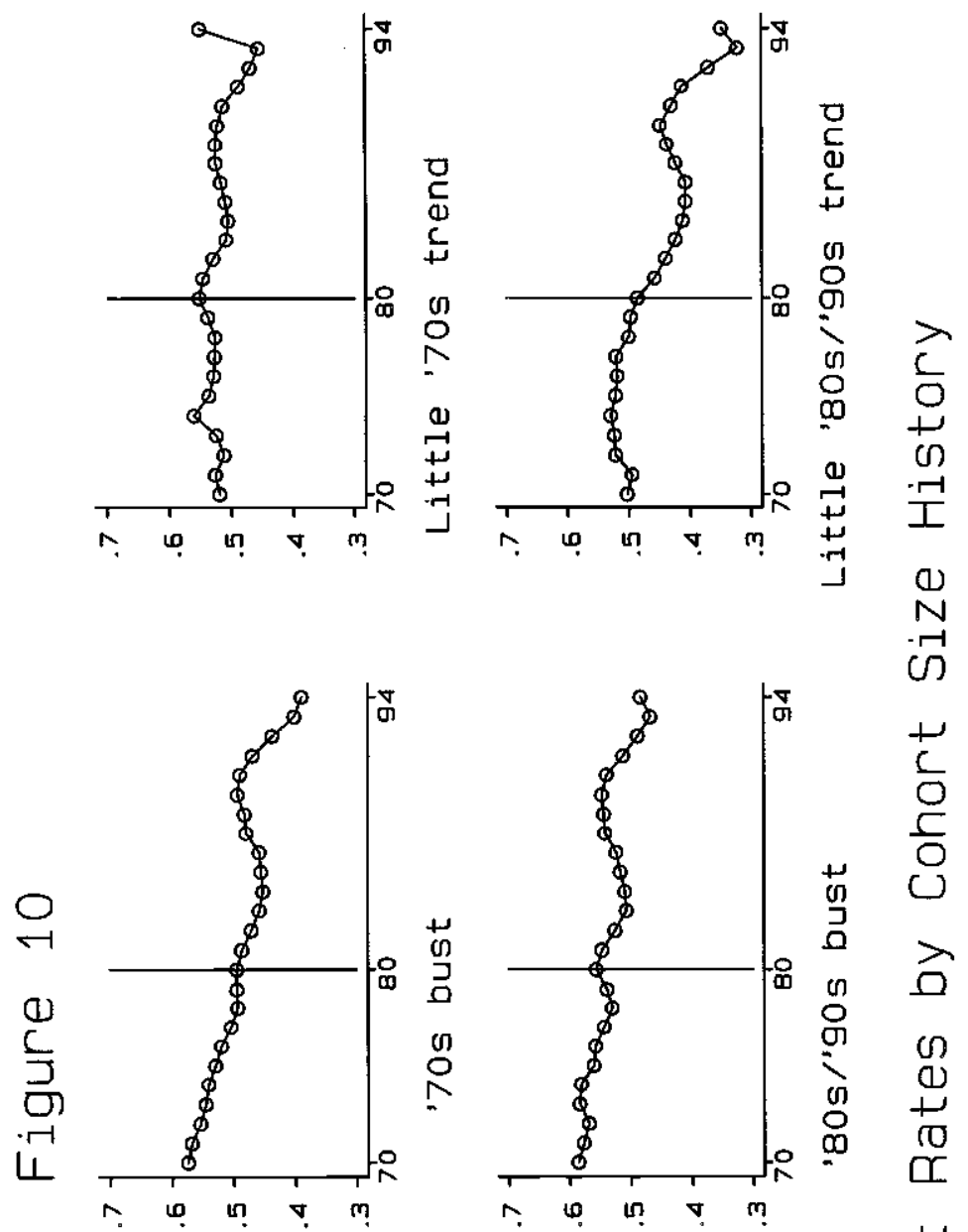

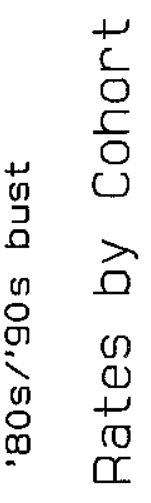

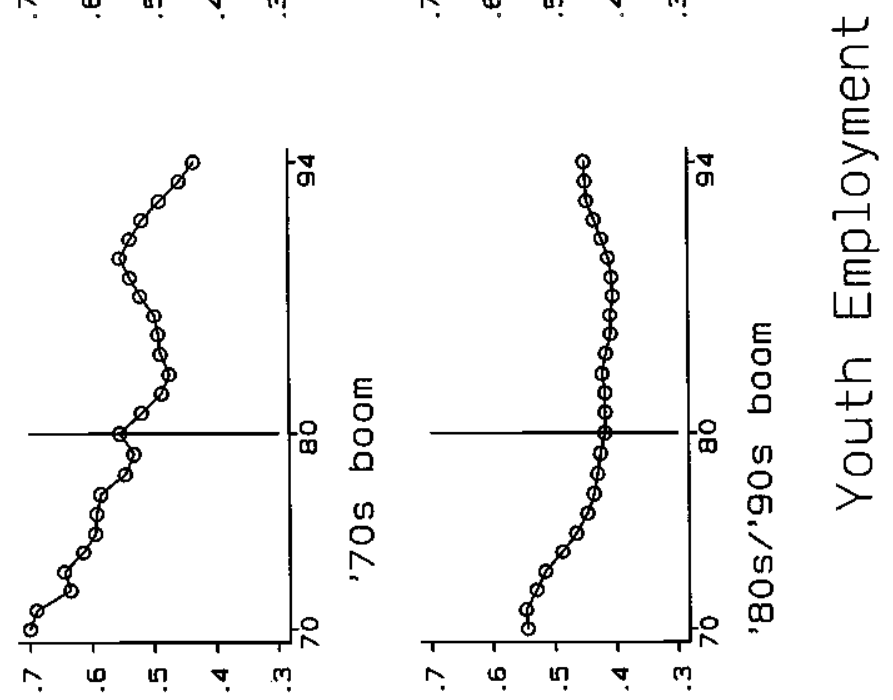

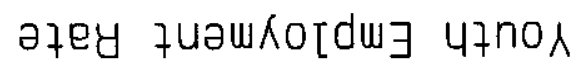




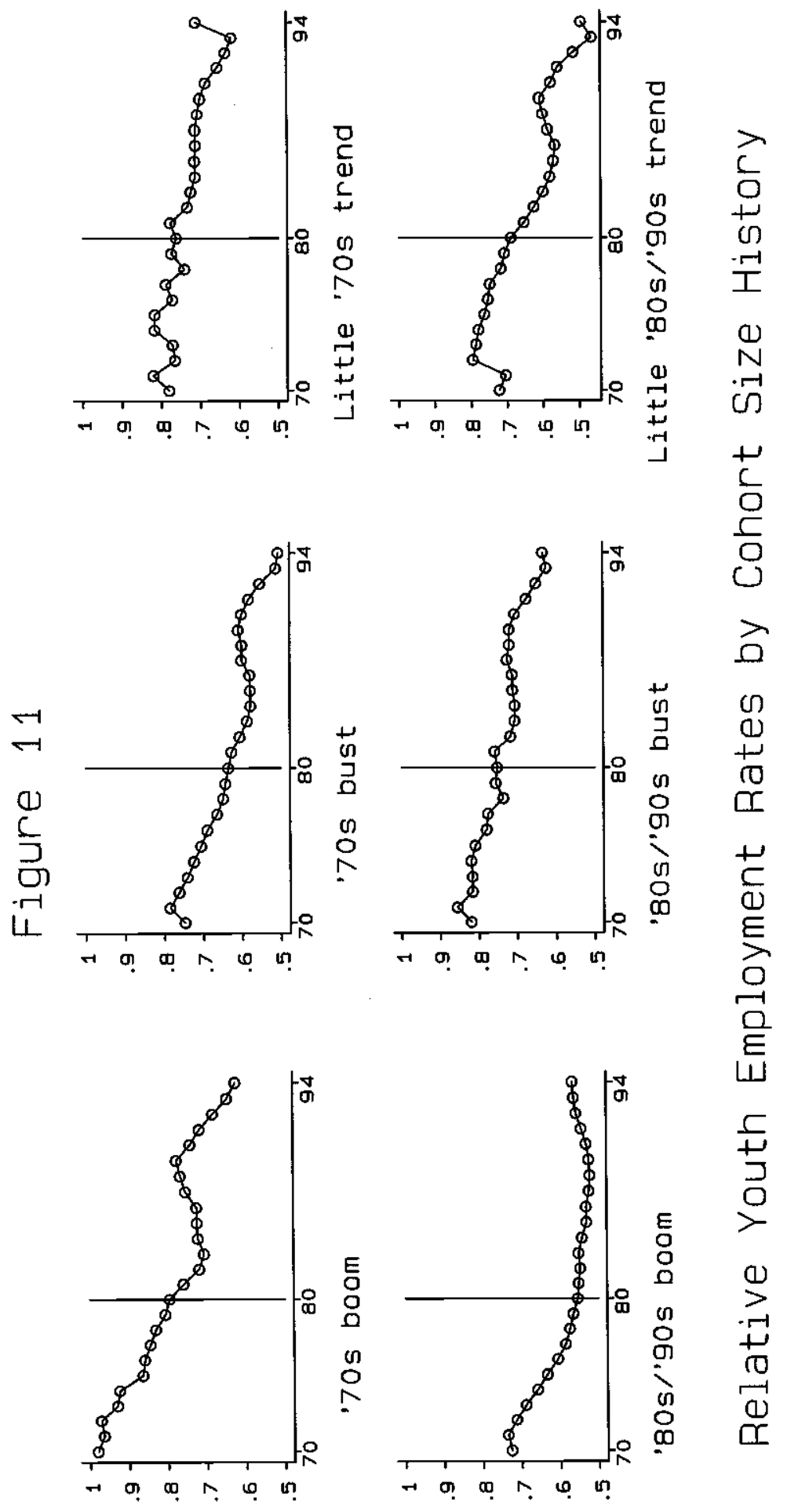

afey quawко[du 


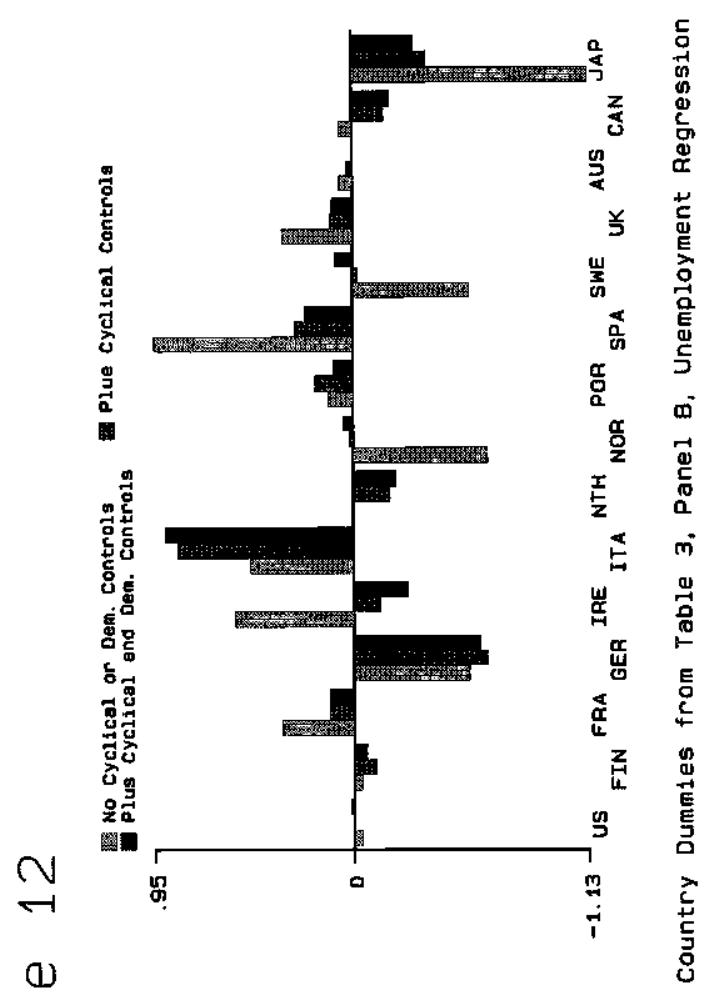

$\frac{0}{5}$

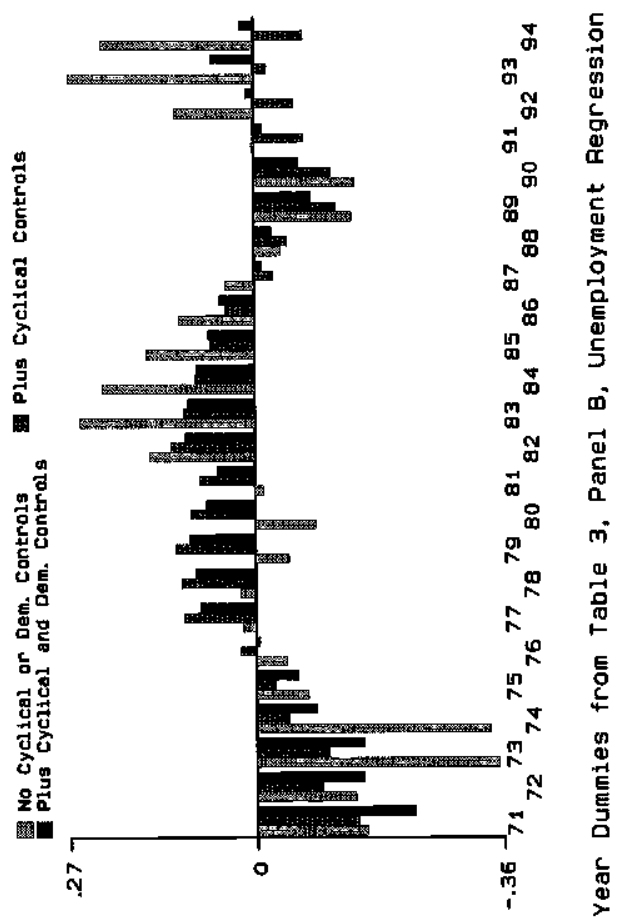




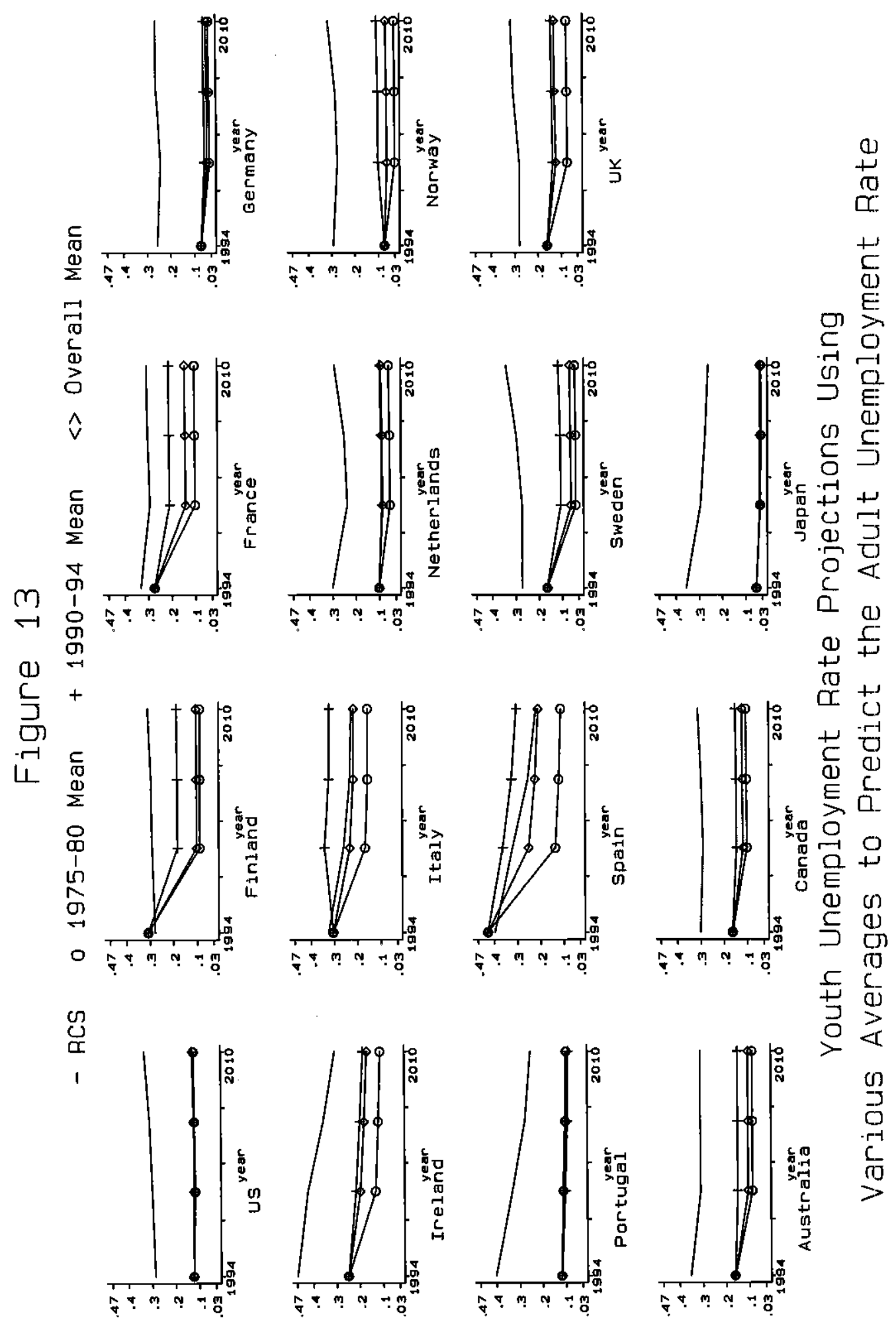


Table 1: Summary of Literature Review

\begin{tabular}{|c|c|c|c|c|}
\hline$\underline{\text { Study }}$ & Country & Outcomes & Prediction for larger cohorts & Evidence \\
\hline Flaim (1979) & U.S. & Unemployment & Higher & Confirmed \\
\hline Flaim (1990) & U.S. & Unemployment & Higher & $\begin{array}{l}\text { Confirmed by fall in } \\
\text { youth rate in } 1980 \text { s. }\end{array}$ \\
\hline $\begin{array}{l}\text { Levine and Mitchell } \\
\text { (1988) }\end{array}$ & U.S. & $\begin{array}{l}\text { Wages } \\
\text { Wage growth }\end{array}$ & $\begin{array}{l}\text { Lower } \\
\text { Lower }\end{array}$ & $\begin{array}{l}\text { Not confirmed } \\
\text { Confirmed }\end{array}$ \\
\hline Nardone (1987) & U.S. & Unemployment & Higher & $\begin{array}{l}\text { Not confirmed; small } \\
\text { entering cohorts were hurt } \\
\text { by early } 80 \text { s recession. }\end{array}$ \\
\hline $\begin{array}{l}\text { Fair and Dominguez } \\
\text { (1991) }\end{array}$ & U.S. & $\begin{array}{l}\text { Wages } \\
\text { Labor supply }\end{array}$ & $\begin{array}{l}\text { Lower } \\
\text { Lower if substitution effect } \\
\text { dominates income effect. }\end{array}$ & $\begin{array}{l}\text { Not studied } \\
\text { Confirmed for women, } \\
\text { not men; income effect } \\
\text { may dominate for men. }\end{array}$ \\
\hline $\begin{array}{l}\text { Stapleton and Young } \\
\text { (1988) }\end{array}$ & U.S. & $\begin{array}{l}\text { Returns to education } \\
\text { College completion }\end{array}$ & $\begin{array}{l}\text { Lower } \\
\text { Lower }\end{array}$ & $\begin{array}{l}\text { Not confirmed by later } \\
\text { aggregate data. } \\
\text { Confirmed by later } \\
\text { aggregate data. }\end{array}$ \\
\hline Berger (1989) & U.S. & Age-wage profile & $\begin{array}{l}\text { Flatter } \\
\text { Steeper if surrounded } \\
\text { by large cohorts, } \\
\text { low earnings but steeper } \\
\text { profiles if born before } \\
\text { or after peak. }\end{array}$ & $\begin{array}{l}\text { Confirmed in his data. } \\
\text { Not confirmed in later } \\
\text { data; but demand factors } \\
\text { may dominate supply in } \\
\text { 1980s/1990s. }\end{array}$ \\
\hline Flinn (1993) & U.S. & Wages & $\begin{array}{l}\text { Direct effect: lower return to } \\
\text { human capital. } \\
\text { Indirect effect: increased human } \\
\text { capital investment } \\
\text { due to lower opportunity cost. } \\
\text { Following large cohorts is good } \\
\text { due to low opportunity } \\
\text { cost and high returns. Leading } \\
\text { a large cohort is bad due to high } \\
\text { cost and low returns due to entry } \\
\text { of large cohort soon to follow. }\end{array}$ & $\begin{array}{l}\text { Simulations confirm } \\
\text { negative but modest } \\
\text { direct effects of size } \\
\text { of own cohort; small } \\
\text { indirect effects. }\end{array}$ \\
\hline Zimmermann (1991) & $\begin{array}{l}\text { Germany, } \\
\text { pre-unification }\end{array}$ & $\begin{array}{l}\text { Age-specific } \\
\text { unemployment }\end{array}$ & $\begin{array}{l}\text { Higher in short run. } \\
\text { Older workers hurt by } \\
\text { large entry cohorts. }\end{array}$ & $\begin{array}{l}\text { Confirmed } \\
\text { Possibly in long run. }\end{array}$ \\
\hline Wright (1991) & Great Britain & Wages & $\begin{array}{l}\text { More depressed for } \\
\text { more-educated members } \\
\text { of large cohorts. }\end{array}$ & $\begin{array}{l}\text { Education differential is } \\
\text { confirmed but overall } \\
\text { effect of large cohort on } \\
\text { wages is temporary. }\end{array}$ \\
\hline Hartog (1993) & Netherlands & Wages & $\begin{array}{l}\text { Lower wages and steeper } \\
\text { experience profiles. }\end{array}$ & Not confirmed \\
\hline
\end{tabular}


Table 1 (continued)

\begin{tabular}{lllll} 
Study & Country & Outcomes & Prediction for larger cohorts & $\begin{array}{l}\text { Evidence } \\
\text { Schmidt (1993) }\end{array}$ \\
Germany & Unemployment & Higher & $\begin{array}{l}\text { Confirmed for a few age- } \\
\text { sex groups, but adverse } \\
\text { effects appear to fade with } \\
\text { age. }\end{array}$ \\
Nickell (1993) & Great Britain & $\begin{array}{l}\text { Relative wage overall } \\
\text { and in union sector. }\end{array}$ & $\begin{array}{l}\text { Lower relative wages if } \\
\text { market conditions affect wages. }\end{array}$ & $\begin{array}{l}\text { Confirmed in both } \\
\text { samples. }\end{array}$ \\
Klevmarken (1993) & Sweden & Wages & Lower wages and wage growth. & Not confirmed \\
\hline
\end{tabular}


Table 2

Estimates of the Effect of the Youth Population Share on the Youth Unemployment and Employment Rates

\begin{tabular}{|c|c|c|c|c|}
\hline & \multicolumn{3}{|c|}{ Independent Variables } & \multirow[b]{2}{*}{$\rho$} \\
\hline Dependent Variable & $\begin{array}{l}\text { Youth Population } \\
\text { Adult Population } \\
\end{array}$ & $\begin{array}{c}\text { Adult Uneinployment } \\
\text { Rate }\end{array}$ & $\begin{array}{l}\text { Adult Employment } \\
\text { Rate }\end{array}$ & \\
\hline \multicolumn{5}{|l|}{ A. Pooled Data } \\
\hline Youth Unemployment Rate & $\begin{array}{l}.035 \\
(.126)\end{array}$ & $\begin{array}{l}.853^{* *} \\
(.025)\end{array}$ & $\begin{array}{l}-.230 \\
(.181)\end{array}$ & n.a. \\
\hline Youth Eniployment Rate & $\begin{array}{l}.481^{* *} \\
(.058)\end{array}$ & $\begin{array}{l}-.070^{* *} \\
(.012)\end{array}$ & $\begin{array}{l}.903 * * \\
(.083)\end{array}$ & n.a. \\
\hline \multicolumn{5}{|l|}{ B. Fixed Country Effects } \\
\hline Youth Unemployinent Rate & $\begin{array}{l}.363^{* *} \\
(.094)\end{array}$ & $\begin{array}{l}.923^{* *} \\
(.018)\end{array}$ & $\begin{array}{l}-.002 \\
(.277)\end{array}$ & n.a. \\
\hline Youth Employment Rate & $\begin{array}{l}.133^{* *} \\
(.045)\end{array}$ & $\begin{array}{l}-, 171^{* *} \\
(.009)\end{array}$ & $\begin{array}{l}.691^{* *} \\
(.133)\end{array}$ & n.a. \\
\hline \multicolumn{5}{|l|}{$\frac{\text { C. Fixed Year and Country }}{\text { Effects }}$} \\
\hline Youth Uneniployment Rate & $\begin{array}{l}.292^{* *} \\
(.095)\end{array}$ & $\begin{array}{l}.800^{* *} \\
(.034)\end{array}$ & $\begin{array}{l}-1.057^{* *} \\
(.374)\end{array}$ & n.a. \\
\hline Youth Employment Rate & $\begin{array}{l}-.112 * * \\
(.050)\end{array}$ & $\begin{array}{c}-.080^{* *} \\
(.018)\end{array}$ & $\begin{array}{c}1.468^{* *} \\
(.197)\end{array}$ & n.a. \\
\hline $\begin{array}{l}\text { D. Fixed Year and Country } \\
\text { Effects with AR Correction }\end{array}$ & & & & \\
\hline Youth Unemployment Rate & $\begin{array}{l}.181 \\
(.149)\end{array}$ & $\begin{array}{l}.689^{* *} \\
(.040)\end{array}$ & $\begin{array}{l}-1.148^{* *} \\
(.473)\end{array}$ & .652 \\
\hline Youth Employment Rate & $\begin{array}{l}.117^{*} \\
(.070)\end{array}$ & $\begin{array}{l}-.047 * * \\
(.013)\end{array}$ & $\begin{array}{l}1.441^{* *} \\
(.177)\end{array}$ & .855 \\
\hline
\end{tabular}

Notes: $\mathrm{N}=342$ in Panels A through C. $\mathrm{N}=320$ in Panel D. ${ }^{*}$ denotes significance at the ten-percent level. ${ }^{* *}$ denotes significance at the five-percent level. All variables are expressed in log form. The data are from 1970 through 1994, although most of the countries do not have data for all of the years. The regressions include dummy variables that account for changes in the data series for some countries. 
Table 3

Fixed Year and Country Effects Estimates Correcting for Serial Correlation and Instrumenting for the Youth Population Share

\begin{tabular}{|c|c|c|c|c|c|}
\hline Dependent Variable & $\begin{array}{l}\text { Youth Population } \\
\text { Adult Population }\end{array}$ & $\begin{array}{c}\text { Adult Unemployment } \\
\text { Rate }\end{array}$ & $\begin{array}{c}\text { Adult } \\
\text { Employment Rate }\end{array}$ & $\begin{array}{c}\text { Hausman test } \\
\text { (p-value) }\end{array}$ & $\rho$ \\
\hline \multicolumn{6}{|l|}{$\frac{\text { A. Using Lagged Births/Adult }}{\text { Population as an Instrument }}$} \\
\hline Youth Unemployment Rate & $\begin{array}{l}.344^{* *} \\
(.168)\end{array}$ & $\begin{array}{l}.693^{* *} \\
(.040)\end{array}$ & $\begin{array}{c}-1.036^{* *} \\
\quad(.479)\end{array}$ & .20 & .651 \\
\hline Youth Employment Rate & $\begin{array}{c}.059 \\
(.087)\end{array}$ & $\begin{array}{l}-.048^{* *} \\
(.014)\end{array}$ & $\begin{array}{l}1.411^{* *} \\
(.181)\end{array}$ & .67 & .855 \\
\hline \multicolumn{6}{|l|}{$\frac{\text { B. Using Lagged Births as an }}{\underline{\text { Instrument }}}$} \\
\hline Youth Unemployment Rate & $\begin{array}{l}.503^{* *} \\
(.202)\end{array}$ & $\begin{array}{l}.695 * * \\
(.040)\end{array}$ & $\begin{array}{l}-.946^{*} \\
(.486)\end{array}$ & .13 & .651 \\
\hline Youth Employment Rate & $\begin{array}{l}-.066 \\
(.105)\end{array}$ & $\begin{array}{l}-.052 * * \\
(.014)\end{array}$ & $\begin{array}{l}1.323^{* *} \\
(.187)\end{array}$ & .11 & .866 \\
\hline
\end{tabular}

Notes: $\mathrm{N}=318 .{ }^{*}$ denotes significance at the ten-percent level. ${ }^{* *}$ denotes significance at the five-percent level. All variables are expressed in $\log$ form. The Hausman tests are for the reported variables only (no dumnies are included in the test). The data are froin 1970 through 1994 , although most of the countries do not have data for all of the years. The regressions include dummy variables that account for changes in the data series for some countries. Two observations are lost relative to Panel D of Table 2 because of missing lagged births data for Japan. 
Table 4

Fixed Year and Country Effects Estimates Correcting for Serial Correlation and Instrumenting for the Youth Population Share with Lagged Births, and Including Lagged GNP Growth Rate as a Cyclical Indicator

\begin{tabular}{|c|c|c|c|c|c|}
\hline & \multicolumn{4}{|c|}{ Independent Variables } & \multirow[b]{2}{*}{$\begin{array}{c}\text { Hausman } \\
\text { test } \\
\text { (p-value) }\end{array}$} \\
\hline Dependent Variable & $\frac{\text { Youth Population }}{\text { Adult Population }}$ & $\begin{array}{l}\text { Lagged GNP } \\
\text { Growth Rate }\end{array}$ & $\begin{array}{l}\text { Adult Unemployment } \\
\text { Rate }\end{array}$ & $\begin{array}{c}\text { Adult } \\
\text { Employment Rate }\end{array}$ & \\
\hline \multicolumn{6}{|l|}{$\frac{\text { A. Only Including the Lagged }}{\text { GNP Growth Rate }}$} \\
\hline Youth Unemployment Rate & $\begin{array}{l}1.119^{* *} \\
(.429)\end{array}$ & $\begin{array}{l}-.018^{* *} \\
(.004)\end{array}$ & -- & $\ldots-$ & .08 \\
\hline Youth Enployment Rate & $\begin{array}{l}-.036 \\
(.154)\end{array}$ & $\begin{array}{l}.003^{* *} \\
(.001)\end{array}$ & -- & $\ldots$ & .97 \\
\hline$\frac{\text { B. Adding the other }}{\text { cyclical indicators }}$ & & & & & \\
\hline Youth Unemployment Rate & $\begin{array}{l}.603^{* *} \\
(.219)\end{array}$ & $\begin{array}{l}-.005^{* *} \\
(.003)\end{array}$ & $\begin{array}{l}.667^{* *} \\
(.045)\end{array}$ & $\begin{array}{c}-1.075^{* *} \\
(.505)\end{array}$ & .06 \\
\hline Youth Employment Rate & $\begin{array}{l}. .030 \\
(.114)\end{array}$ & $\begin{array}{l}.001 \\
(.001)\end{array}$ & $\begin{array}{l}-.064^{* *} \\
(.016)\end{array}$ & $\begin{array}{c}1.285 * * \\
(.199)\end{array}$ & .48 \\
\hline
\end{tabular}

Notes: $\mathrm{N}=293 .{ }^{*}$ denotes significance at the ten-percent level. ${ }^{* *}$ denotes significance at the five-percent level. All variables are expressed in log form.

The Hausman tests are for the reported variables only (no dummies are included in the test). The data are from 1970 through 1994, although most of the countries do lot have data for all of the years. The regressions include dunnny variables that account for clianges in the data series for some countries.

Observations are lost relative to Panel B of Table 3 because of missing data on the lagged GNP growth rate. The mean of the lagged GNP growth rate is 2.715 with a standard deviation is 2.603 . The results for Panel B of this table without the lagged GNP growth rate, but using the smaller sample size are qualitatively the same as the results in Table 3. 
Table 5

Fixed Year and Country Effects Estimates Correcting for Serial Correlation and Instrumenting for the Youth Population Share with Lagged Births, by Sex

\begin{tabular}{|c|c|c|c|c|c|}
\hline & \multicolumn{4}{|c|}{ Independent Variables } & \multirow[b]{2}{*}{$\begin{array}{c}\text { Hausman } \\
\text { test } \\
\text { (p-value) }\end{array}$} \\
\hline Dependent Variable & $\frac{\text { Youth Population }}{\text { Adult Population }}$ & $\begin{array}{c}\text { Adult } \\
\text { Unemployment Rate }\end{array}$ & $\begin{array}{c}\text { Adult } \\
\text { Employment Rate }\end{array}$ & $\begin{array}{l}\text { Lagged GNP } \\
\text { Growth Rate }\end{array}$ & \\
\hline \multicolumn{6}{|l|}{$\underline{\text { A. Men }}$} \\
\hline $\begin{array}{c}\text { Youth Unemployment } \\
\text { Rate }\end{array}$ & $\begin{array}{l}.123 \\
(.228)\end{array}$ & $\begin{array}{l}.827^{* *} \\
(.049)\end{array}$ & $\begin{array}{l}-.466 \\
(.582)\end{array}$ & -- & .35 \\
\hline Youth Employment Rate & $\begin{array}{l}-.008 \\
(.119)\end{array}$ & $\begin{array}{l}-.074^{* *} \\
(.017)\end{array}$ & $\begin{array}{l}1.058^{* *} \\
(.228)\end{array}$ & $\cdots$ & .37 \\
\hline $\begin{array}{c}\text { Youth Unemployment } \\
\text { Rate }\end{array}$ & $\begin{array}{l}.836 * \\
(.474)\end{array}$ & -- & -- & $\begin{array}{c}-.023 * * \\
(.005)\end{array}$ & .12 \\
\hline Youth Employment Rate & $\begin{array}{l}.046 \\
(.166)\end{array}$ & -- & $\cdots$ & $\begin{array}{l}.005^{* *} \\
(.001)\end{array}$ & .82 \\
\hline \multicolumn{6}{|l|}{ B. Women } \\
\hline $\begin{array}{c}\text { Youth Unemployment } \\
\text { Rate }\end{array}$ & $\begin{array}{l}.899 * * \\
(.221)\end{array}$ & $\begin{array}{l}.568^{* *} \\
(.045)\end{array}$ & $\begin{array}{c}-1,220^{* *} \\
(.537)\end{array}$ & -- & .09 \\
\hline Youth Employment Rate & $\begin{array}{l}-.142 \\
(.104)\end{array}$ & $\begin{array}{l}-.023^{*} \\
(.013)\end{array}$ & $\begin{array}{c}1.743^{* *} \\
(.182)\end{array}$ & -- & .01 \\
\hline $\begin{array}{c}\text { Youth Unemployment } \\
\text { Rate }\end{array}$ & $\begin{array}{c}1.435^{* *} \\
(.408)\end{array}$ & -- & --- & $\begin{array}{c}-.013^{* * *} \\
(.004)\end{array}$ & .04 \\
\hline Youth Employment Rate & $\begin{array}{l}-.142 \\
(.159)\end{array}$ & -- & $\cdots$ & $\begin{array}{l}.002 * \\
(.001)\end{array}$ & .09 \\
\hline
\end{tabular}

Notes: $\mathrm{N}=318$ in the first two rows of Panels $\mathrm{A}$ and $\mathrm{B} . \mathrm{N}=293$ in the second two rows. Observations are lost because of incomplete data on lagged GNP growth rates. * denotes significance at the ten-percent level. ** denotes significance at the five-percent level. All variables are expressed in $\log$ form. The Hausman tests are for the reported variables only (no dummies are included in the test). The data are from 1970 through 1994; although most of the countries do not have data for all of the years. The regressions include dumny variables that account for changes in the data series for some countries. 
Table 6

Fixed Year and Country Effects Estimates Correcting for Serial Correlation and Instrumenting for the Youth Population Share with Lagged Births, Including Interactions of the Adult Unemployment Rate

\begin{tabular}{|c|c|c|c|c|c|}
\hline & \multicolumn{4}{|c|}{ Independent Variables } & \multirow[b]{2}{*}{$\begin{array}{c}\text { Hausman } \\
\text { test } \\
\text { (p-value) }\end{array}$} \\
\hline Dependent Variable & $\frac{\text { Youth Population }}{\text { Adult Population }}$ & $\begin{array}{c}\text { Interaction with } \\
\text { the Youth } \\
\text { Population Share }\end{array}$ & $\begin{array}{c}\text { Adult } \\
\begin{array}{c}\text { Unemploynuent } \\
\text { Rate }\end{array} \\
\end{array}$ & $\begin{array}{c}\text { Adult } \\
\text { Employment } \\
\text { Rate } \\
\end{array}$ & \\
\hline Youth Unemployment Rate & $\begin{array}{l}.626 * * \\
(.204)\end{array}$ & $\begin{array}{l}-.399^{* *} \\
(.158)\end{array}$ & $\begin{array}{l}.304^{*} \\
(.160)\end{array}$ & $\begin{array}{l}-.843^{*} \\
(.484)\end{array}$ & .11 \\
\hline Youth Employment Rate & $\begin{array}{l}-.082 \\
(.104)\end{array}$ & $\begin{array}{l}.095^{*} \\
(.053)\end{array}$ & $\begin{array}{c}.041 \\
(.054)\end{array}$ & $\begin{array}{c}1.314^{* *} \\
(.187)\end{array}$ & .05 \\
\hline
\end{tabular}

Notes: $\mathrm{N}=318 .{ }^{*}$ denotes significance at the ten-percent level. ${ }^{* *}$ denotes significance at the five-percent level. All variables are

expressed in $\log$ form. The Hausman tests are for the reported variables only (no dummies are included in the test). The data are from

1970 through 1994, although most of the countries do not have data for all of the years. The regressions include dummy variables that account for changes in the data series for some countries. The youth population share is interacted with (adult unemployment rate mean adult unemployment rate). 
Table 7

Fixed Year and Country Effects Estimates Correcting for Serial Correlation and Instrumenting for the Youth Population Share

Including Enrollment Rates

\begin{tabular}{|c|c|c|c|c|c|c|}
\hline Dependent Variable & $\begin{array}{l}\text { Youth Population } \\
\text { Adult Population }\end{array}$ & $\begin{array}{c}\text { Adult } \\
\text { Unemployment } \\
\text { Rate } \\
\end{array}$ & $\begin{array}{c}\text { Adult } \\
\text { Eniployment } \\
\text { Rate } \\
\end{array}$ & $\begin{array}{c}\text { Youth } \\
\text { Enrollment } \\
\text { Rate } \\
\end{array}$ & $\begin{array}{c}\text { Hausman } \\
\text { test } \\
\text { (p-value) }\end{array}$ & $\rho$ \\
\hline $\begin{array}{l}\text { Youth Unemployment } \\
\text { Rate }\end{array}$ & $\begin{array}{l}.073 \\
(.421)\end{array}$ & $\begin{array}{l}.700^{* *} \\
(.095)\end{array}$ & $\begin{array}{l}-.192 \\
(.691)\end{array}$ & --- & .49 & .573 \\
\hline Youth Employment Rate & $\begin{array}{l}-.383 \\
(.284)\end{array}$ & $\begin{array}{l}-.098^{*} \\
(.051)\end{array}$ & $\begin{array}{l}.556 \\
(.377)\end{array}$ & -- & .75 & .683 \\
\hline $\begin{array}{c}\text { Youth Unemployment } \\
\text { Rate }\end{array}$ & $\begin{array}{l}.123 \\
(.422)\end{array}$ & $\begin{array}{l}.696 * * \\
(.097)\end{array}$ & $\begin{array}{l}-.197 \\
(.704)\end{array}$ & $\begin{array}{l}-.029 \\
(.126)\end{array}$ & .59 & .548 \\
\hline Youth Einployment Rate & $\begin{array}{l}-.343 \\
(.250)\end{array}$ & $\begin{array}{l}-.075 \\
(.053)\end{array}$ & $\begin{array}{l}.604 \\
(.386)\end{array}$ & $\begin{array}{l}-.130^{*} \\
(.070)\end{array}$ & .99 & .603 \\
\hline
\end{tabular}

Notes: $\mathrm{N}=120 .{ }^{*}$ denotes significance at the ten-percent level. ${ }^{* *}$ denotes significance at the five-percent level. All variables are expressed in log form. The Hausman tests are for the reported variables only (no dummies are included in the test). The data are from 1970 through 1994, although most of the countries do not have data for all of the years. Figures 6 and 7 show the data series of enrollment rates available for each country. The regressions include dummy variables that account for changes in the data series for some countries. 


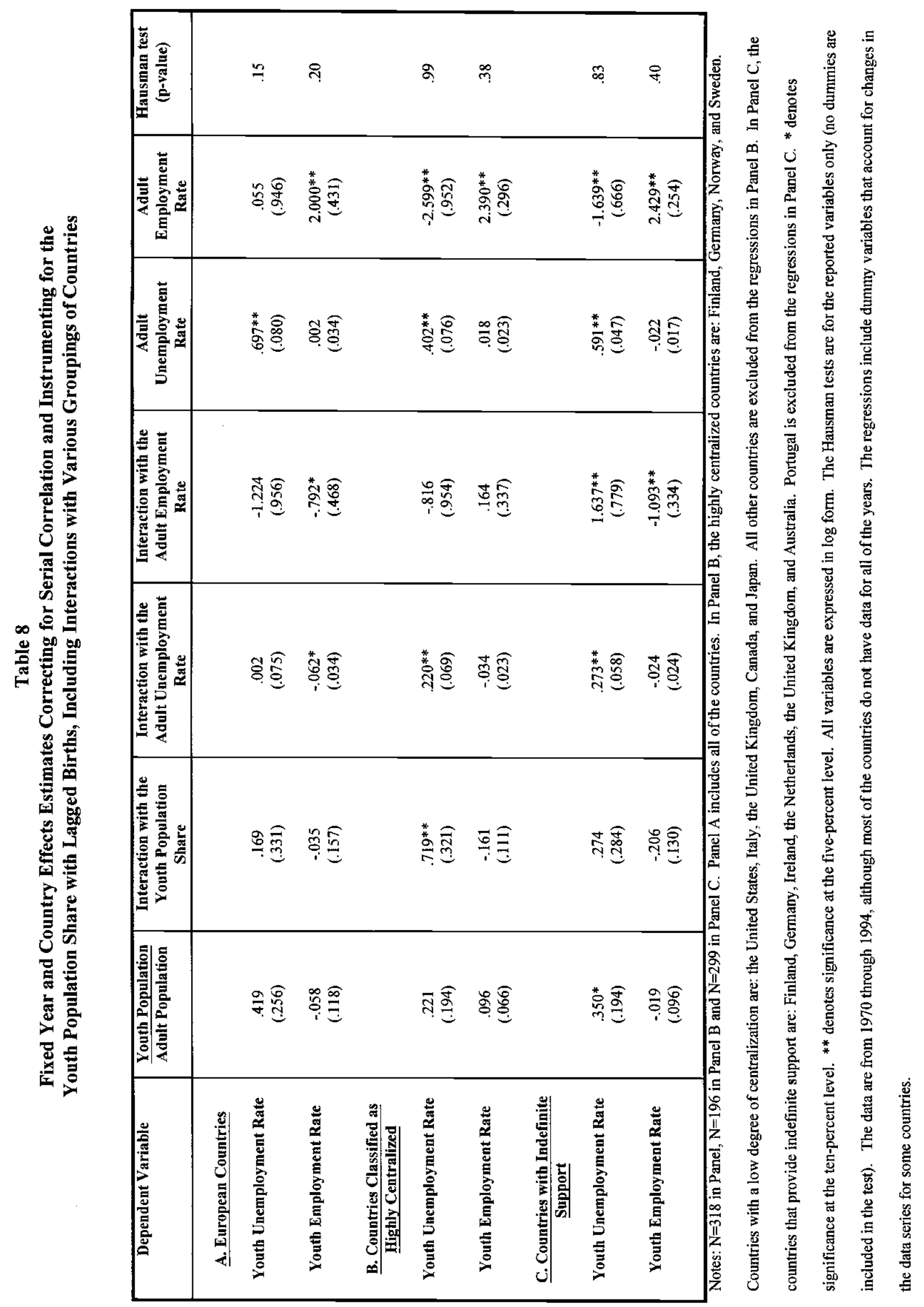




\section{Appendix: Literature Review}

This appendix reviews the findings of recent studies, which are summarized in Table 1

of the paper (along with some studies not discussed below). In general, recent studies continue to confirm earlier studies in finding effects of cohort size on relative earnings and employment or unemployment. However, this is not always the case. Few studies examine both employment and earnings. A few have analyzed longitudinal data sources in an attempt to distinguish period from cohort effects and to examine effects on the age-earnings profiles, but they have yielded limited insight due to the short length of panels.

\section{Summary of Recent Studies}

Looking first at evidence for the U.S., Flaim (1979) studies the effects of demographic changes on the U.S. unemployment rate. Simple decomposition exercises suggest that 1 percentage point of a 2.7 percentage point increase in the unemployment rate in the U.S. between 1957 and 1977 is due to changing demographic (age and sex) composition of the labor force. Allowing interactions suggests that the "pure" effects of changing demographic composition are lower, the remainder being accounted for by positive interactions between changes in size and changes in group-specific unemployment rates (e.g., cohort crowding). Flaim also finds a positive correlation between the percentage of teens in the population and the gap between the unemployment rate of teens and adults. He predicted that the overall unemployment rate would fall about .4 percentage point between 1977 and 1990 (from about 7.0 percent). In a follow-up study published in 1990 , Flaim shows indeed that the unemployment rate fell by about one-half point between 1979 and 1989, and argues that the decline is accounted for by declining youth cohort sizes. However, there appears to be no attempt to control for the state of the macro economy or for wage changes. One must wonder why, if supply shifts (smaller youth cohorts) explain declining unemployment rates, youth 
wages rates fell relative to the wages of older workers in this period.

Nardone (1987) shows that the early 1980s recession hurt youths even though they were a small fraction of the labor force. This finding seems to conflict with the results of Flaim, but also underscores the difficulty of distinguishing period, age, and cohort effects. The present difficulty arises from a well-known age-period interaction: i.e., labor market outcomes for younger workers appear to be more responsive to economic recessions than are outcomes for older workers (e.g., Clark and Summers, 1981). This finding suggests that researchers should control for the business cycle even when studying the relative unemployment rates (or employment rates) of youths to adults.

Fair and Dominguez (1991) predict that entry of large cohorts should depress wages of young workers, lowering labor supply if the substitution effect dominates the income effect in labor supply decisions. Estimates of a simple empirical model indicate that the income effect dominates for men, but not for women. (The implied magnitudes of the substitution and income effects are consistent with the labor supply literature (e.g., Killingsworth, 1983).) They admit, however, that both cohort size and age effects could be contaminated by business cycle effects.

Other researchers have examined additional implications of changing population age structure. Stapleton and Young (1988) note that the U.S. baby boomers affected the rate of return to education as well as the average level of educational attainment. If substitutability between younger and older workers declines as education increases, the present value of lifetime earnings is depressed more for highly-educated workers from large cohorts, reducing incentives to invest. This implies that the return to education and college completion rates would fall for baby boomers, while educational attainment should increase for post-babyboomers. They study a sample from 1973 to 1980 and note a decrease from 30 to 23 percent 
in the fraction of 22 year-old males who completed college, although completion among females increased steadily. They project that college completion rates would rise in the mid1980s and continue to climb, as in fact occurred.

Berger (1989) studies a sample of white males drawn from the March CPS from 1968 to 1984 , arguing for the importance of accounting for position in the demographic cycle, in addition to cohort size, in estimating the effect of demographic change on youth labor markets. Members of large cohorts can expect flatter wage profiles, those surrounded by large cohorts can expect steeper profiles, and those in cohorts born just before or after demographic peaks should expect lower initial earnings but steeper profiles. Berger argues that larger cohorts will invest less in human capital because they anticipate low returns; young and old workers are poor substitutes if they are highly educated, so the returns to education will be relatively low for members of large cohorts. His model assumes static demand for educated labor. In the 1980s and 1990s increases in the demand for educated workers may have swamped the effects of any changes in supply, although in some countries the entry of smaller cohorts may have contributed to the increase in the returns to education.

Building on the work of Stapleton and Young, Berger, and his own earlier work, Flinn (1993) develops a model of cohort size and human capital investment. In particular, he examines the effects of changes in the number of "investors" on the returns to investment, assuming different cohorts are perfect substitutes, in two models: one in which investors have perfect foresight, and the other in which expectations are static. The focus is on investment in on-the-job training (OJT). There are time-dependent demand shifts such as trade or productivity shocks. The cohort size sequence is known and the return to investment is given. Entrants maximize present value of lifetime income. All cohort size effects are reflected in the sequence of rental rates for human capital, which are determined by cohort size and investment 
-A.4-

decisions. Cohort size perturbations have direct and indirect effects. Direct effects are those holding investment constant; indirect effects allow human capital to adjust. The model is calibrated with U.S. data on white male age distributions from 1880 to 2010 at 10 year intervals, and average white male wages in U.S. manufacturing from 1925 to 1985 . Youths are aged 15-24.

Results from the simulation suggest that the elasticity of own wage with respect to cohort size is negative but small. The reason is that increases in cohort size reduce the opportunity cost of investment which serves to offset the lower return. Flinn also predicts that being a member of a cohort that "follows" a large cohort has a large positive effect on one's wages because opportunity costs of investment decline with no decreased return; similarly, he predicts a large adverse effect of being on the leading edge of a demographic cycle because many highly-trained workers will follow in the near future, driving down the return to investment. The elasticity of wealth with respect to cohort size is negative (about -.25 for own cohort size). Also, Flinn finds little difference between direct and indirect effects. Simulations suggest that wealth was depressed 20 to 30 percent for baby boomers (compared to a scenario of constant population sizes).

A number of researchers have also considered evidence on these questions using data from European countries. Zimmermann (1991) examines the effects of aging and cohort size on age-specific unemployment rates in pre-unification Germany. He uses aggregate time-series data from 1967 to 1988 on younger workers (aged 15-34) and older workers (aged 35-54). Pre-reunification Germany makes an interesting country study because there are large withincountry variations between men and women in relative cohort size due to high male mortality in WWII. The effects of cohort size are larger in the short run than the long run, confirming the hypothesis of (at least partial) catch-up. In particular, he finds a significant positive effect 


\section{$-\mathrm{A} .5-$}

of cohort size on unemployment that appears to decline with age, controlling for the business cycle. Large cohorts of younger workers do not affect the unemployment rates of older cohorts in the short run, suggesting a short-run adverse effect of cohort size on relative unemployment of youth. However, his estimates suggest that older workers, especially males, may be hurt in the long run by the entry of a large cohort.

Wright (1991) studies cohort size and earnings in Great Britain. The sample is composed of male heads of household from the General Household Survey, 1973 to 1982. Wright hypothesizes a greater impact of cohort crowding for more-educated workers. Therefore, he conducts separate analyses for three education groups and 31 age groups, over 10 years, although he does not create education-specific cohort size controls because educational attainment is thought to be endogenous. Wright finds that the effects of cohort size are indeed bigger for the more highly-educated individuals. He finds some evidence of lower earnings in larger cohorts, but these earnings differences do not persist as the cohort ages. However, the period 1973 to 1982 may not have been a good choice for the study of cohort size effects on the relative earnings of youth because of a modest and approximately linear increase in the size of the young/old population ratio (15-29/30-64; Fig. 2 of his paper).

Hartog, et al. (1993) study effects of cohort size in a sample of Dutch males in 1979, 1985 and 1988, stratified by education group. They find significant positive effects of cohort size on earnings, and negative cohort size-experience interactions, which are significant for workers with lower levels of educational attainment. These signs are the reverse of those found in other studies. Their Table 8.9 presents a specification check. First, in a simple cross section, they do find a significant negative cohort size "main effect." Second, with experience and age controls, the effect is small, negative, and not significant. Third, when they drop school and age controls, significant negative effects return. Finally, when they control for age 


\section{-A.6-}

alone, there is no significant effect. Hartog, et al. note that the sensitivity of the cohort size estimates may be due to collinearity between age and cohort size in a single cross section. In his discussion of this paper, Wright (1993) comments that the reverse effects may not be a mystery because the authors neglect to measure cohorts' positions in the demographic cycle.

Schmidt (1993) examines population aging and unemployment in Germany. He does not consider relative wages because "wage adjustment is hampered by a strong monopoly union" (p. 216). In recent years in Germany, there has been a reversal of relative unemployment rates, with those for older workers actually exceeding those for younger workers. He finds adverse effects of large cohort size for a few age-sex groups. In particular, effects of cohort size on unemployment are positive and significant for ages $15-19,20-24$, and 55-59 (males and females), but not for other ages. This result is consistent with a cohort size effect on unemployment that does not persist into prime working ages. Consistent with Flinn, Schmidt notes that two issues--the persistence of cohort size effects and the effects on investment in human capital--are linked. He finds that the relative wage structure is fairly constant, but notes that births are not the only demographic factor to affect the relative size of the labor force at different ages.

Nickell (1993) examines effects of relative cohort size on the relative wages of young men in Britain from 1961 to 1989 . He carries out two sets of analyses: one for the general labor market, the other for the unionized sector. Both analyses suggest substantial adverse effects of cohort size on the relative wages of youth, controlling for the proportion of youth enrolled in school, and cyclical demand factors.

Klevmarken (1993) focuses more on the effects of population aging on earnings mobility. Age-earnings profiles should be sensitive to supply and demand shifts (see his Figures 7.1 and 7.2). For example, secular increases in productivity will lead cross-section 
estimates of age-earnings profiles to be biased downward. Entry of large youth cohorts will tend to steepen cross-section age-earnings profiles. Klevmarken reviews studies of the effects of cohort size on age-earnings profiles (Freeman, 1979; Welch, 1979; Berger, 1985; Stapleton and Young, 1988; Berger, 1989; Martin and Ogawa, 1988; Wright, 1991; Jonsson and Klevmarken, 1978; Tarsian and Gustaffson, 1991; Murphy, Plant and Welch, 1988). The point of greatest contention appears to be the extent of "catch-up" in earnings for members of large cohorts. Klevmarken in particular questions Berger's (1989) results which suggest that catch up does not take place. Murphy, et al. (1988) find an "initial" (short run) elasticity of 10 percent with respect to cohort size that falls to three percent on a lifetime basis. Tarsian and Gustaffson find that wages of Swedish shop assistants are depressed by large cohort size, but profiles are steeper.

Klevmarken conducts an analysis of a Swedish panel data set for the period 1984 to 1988 at two-year intervals. His relative cohort size measure is the weighted average of own and surrounding age groups. He notes that immigration flows are large and poorly measured. He finds that all cohort size variables are insignificant, and concludes that "Another result, supported both by this and previous studies, is that earnings profiles are more sensitive to changes in demand than to supply side changes" (p. 167). However, we note that the models contain many interaction terms that make interpretation difficult. 


\section{Supplemental References for Appendix}

Berger, Mark C. 1985. "The Effect of Cohort Size on Earnings Growth: A Reexamination of the Evidence." Journal of Political Economy 93: 561-73.

Berger, Mark C. 1989. "Demographic Cycles, Cohort Size, and Earnings." Demography 26: 311-21.

Clark, Kim B. and Lawrence H. Summers. 1981. "Demographic Differences in Cyclical Employment Variation." Journal of Human Resources 16(1): 61-79.

Ermisch, John. 1993. "Comment on Schmidt." In Paul Johnson and Klaus F. Zimmermann, eds. Labour Markets in an Ageing Europe (Cambridge: Cambridge University Press).

Freeman, Richard B. 1979. "The Effect of Demographic Factors on Age Earnings Profiles." Journal of Human Resources 14: 289-318.

Jonsson, A., and N.A. Klevmarken. 1978. "On the Relationship between CrossSectoral and Cohort Earnings Profiles." Annales de l'INSEE: 331-53. Press).

Killingsworth, Mark R. 1983. Labor Supply (Cambridge: Cambridge University

Martin, Linda G., and Naohiro Ogawa. 1993. "The Effect of Cohort Size on Relative Wages in Japan." In Ronald D. Lee, W. Brian Arthur, and Gerry Rodgers, eds. Economics of Changing Age Distributions in Developing Countries (Oxford: Oxford University Press).

Murphy, Kevin, Mark Plant, and Finis Welch. 1988. "Cohort Size and Earnings in the United States." In Ronald D. Lee, W. Brian Arthur, and Gerry Rodgers, eds. Economics of Changing Age Distributions in Developing Countries (Oxford: Oxford University Press).

Tasiran, A., and Gustafsson, B. 1991. "The Monthly Wage Earnings of Salesmen and Shop Assistants." Working Paper, Department of Economics, Gothenburg University.

Welch, Finis. 1979. "Effects of Cohort Size on Earnings: The Baby Boom Babies' Financial Bust." Journal of Political Economy 87: S65-S97.

Wright, Robert E. 1993. "Comment on Hartog, Oosterbeek and Teulings." In Paul Johnson and Klaus F. Zimmermann, eds. Labour Markets in an Ageing Europe (Cambridge: Cambridge University Press). 